\title{
Sustained release of hepatocyte growth factor by cationic self-assembling peptide/heparin hybrid hydrogel improves $\beta$-cell survival and function through modulating inflammatory response
}

\author{
This article was published in the following Dove Press journal: \\ International Journal of Nanomedicine \\ 23 September 2016 \\ Number of times this article has been viewed
}

\section{Shuyun Liu' \\ Lanlan Zhang ${ }^{2}$ \\ Jingqiu Cheng' \\ Yanrong Lu' \\ Jingping Liu'}

'Key Laboratory of Transplant Engineering and Immunology,

West China Hospital, ${ }^{2}$ Institute for Nanobiomedical Technology and

Membrane Biology, Sichuan University, Chengdu, People's Republic of China
Correspondence: Yanrong Lu; Jingping Liu Key Laboratory of Transplant Engineering and Immunology, West China Hospital,

No I Keyuan 4th Road, Gaopeng

Avenue, Chengdu 61004I,

People's Republic of China

Tel +862885164029

Fax +862885164030

Email luyanrong@scu.edu.cn;

liujingping@scu.edu.cn

\begin{abstract}
Inflammatory response is a major cause of grafts dysfunction in islet transplantation. Hepatocyte growth factor (HGF) had shown anti-inflammatory activity in multiple diseases. In this study, we aim to deliver HGF by self-assembling peptide/heparin (SAP/Hep) hybrid gel to protect $\beta$-cell from inflammatory injury. The morphological and slow release properties of SAPs were analyzed. Rat INS-1 $\beta$-cell line was treated with tumor necrosis factor $\alpha$ in vitro and transplanted into rat kidney capsule in vivo, and the viability, apoptosis, function, and inflammation of $\beta$-cells were evaluated. Cationic KLD1R and KLD2R self-assembled to nanofiber hydrogel, which showed higher binding affinity for Hep and HGF because of electrostatic interaction. Slow release of HGF from cationic SAP/Hep gel is a two-step mechanism involving binding affinity with Hep and molecular diffusion. In vitro and in vivo results showed that HGF-loaded KLD2R/Hep gel promoted $\beta$-cell survival and insulin secretion, and inhibited cell apoptosis, cytokine release, T-cell infiltration, and activation of NFkB/p38 MAPK pathways in $\beta$-cells. This study suggested that SAP/Hep gel is a promising carrier for local delivery of bioactive proteins in islet transplantation.
\end{abstract}

Keywords: self-assembling peptide, islet transplantation, inflammation, HGF, slow release

\section{Introduction}

Islet transplantation is considered as an effective treatment for insulin-dependent diabetes mellitus. ${ }^{1}$ However, high rate of early islet dysfunction markedly reduced the outcome of islet transplantation. ${ }^{2,3}$ Previous study indicated that up to $60 \%$ of islet grafts were lost in the early period following transplantation. ${ }^{1}$ Although the mechanism involved in islet injury is very complex, increased evidence indicate that inflammation is a major cause for early islet graft loss. ${ }^{2}$ It had been found that proinflammatory factors such as interleukin $1 \beta$ (IL-1 $\beta$ ) and tumor necrosis factor $\alpha$ (TNF- $\alpha$ ) increased in islet grafts posttransplantation. ${ }^{3}$ The infiltration of proinflammatory cells such as macrophages and $\mathrm{T}$ lymphocytes in islet grafts also contributed to $\beta$-cell injury. ${ }^{4}$ Therefore, inhibiting inflammation may protect the transplanted islets and improve the therapeutic efficiency of islet transplantation.

Previous studies reported that anti-inflammation is a helpful strategy for the improvement of islet grafts survival and function. ${ }^{5,6}$ Administration of anti-inflammatory compounds enhanced graft survival by inhibiting expression of cytokines and apoptosis in a syngeneic islet transplant model. ${ }^{5}$ Clinical results also showed that coadministration 
of TNF- $\alpha$ inhibitor improved both early and long-term islet grafts function in human islet transplantation. ${ }^{6}$ Hepatocyte growth factor (HGF) is a pleiotropic growth factor (GF) secreted by mesenchymal cells, which play important roles in promoting motility, proliferation, and morphogenesis of epithelia through its receptor c-Met. ${ }^{7}$ HGF showed protective effect in many inflammatory and autoimmune diseases, such as rheumatoid arthritis, neuroinflammation, and chronic kidney diseases. ${ }^{8}{ }^{8}$ HGF could directly inhibit renal inflammation and chemokines expression by disrupting NF $\kappa B$ signaling pathway. ${ }^{9,10}$ It also showed positive effects on glucose sensing, mitogenesis, and survival of $\beta$-cells. ${ }^{11}$ Therefore, local release of anti-inflammatory HGF may enhance islet grafts survival and function.

Self-assembling peptide (SAP) is a type of designed biomaterial that consists of natural amino acids. ${ }^{12,13}$ Some SAPs could self-assemble to nanofibers and further change to hydrogels under physiological saline conditions. SAPs had been widely used in various biomedical applications including cell culture, tissue engineering, and drug delivery. ${ }^{12-15}$ RADA16 peptide was used to release smallmolecule compounds and GFs, and the results showed that these molecules rapidly diffused through the hydrogel and resulted in a fast release of GFs. ${ }^{16,17}$ Therefore, improved SAP for slow release of small-molecule compounds and GFs is needed. Heparin (Hep) is a sulfated glycosaminoglycan with high binding affinity for various GFs such as vascular endothelial growth factor and basic fibroblast growth factor through molecular shape recognition and electrostatic interaction. Hep also protected GFs from thermal denaturation and proteinase degradation, and it has been widely used to immobilize GFs on biomaterials. ${ }^{18}$ Therefore, incorporation of Hep in SAP gels might be a promising method to stabilize and slow release of GFs for islet transplantation.

In this study, we developed a series of cationic SAPs by the addition of arginine (R) in the KLD12 (KLD) peptide, and evaluated their binding affinity for Hep and the release rate of HGF in SAP/Hep hybrid gel (Figure 1A). We also evaluated the protective effect of HGF-loaded SAP/Hep gel on viability, apoptosis, insulin secretion, and inflammation of INS-1 $\beta$-cell line by using in vitro cytokine injury and in vivo transplantation model.

\section{Materials and methods SAP synthesis}

SAPs (Table 1) were commercially synthesized by Shanghai Bootech Bioscience \& Technology Co., Ltd. (Shanghai, People's Republic of China). Peptides were purified to higher than
Table I Physicochemical properties of self-assembling peptides

\begin{tabular}{llll}
\hline Peptide & Sequence & $\begin{array}{l}\text { Molecular weight } \\
\mathbf{( M W , ~ D a )}\end{array}$ & $\begin{array}{l}\text { Net charge } \\
\mathbf{( p H = 7 )}\end{array}$ \\
\hline KLD & KLDLKLDLKLDL & $\mathrm{I}, 467.8$ & Neutral \\
KLDIR & KLDLKLDLKLDLR & $\mathrm{I}, 582.9$ & + \\
KLD2R & KLDLKLDLKLDLRR & $\mathrm{I}, 739.1$ & ++ \\
KLD3R & KLDLKLDLKLDLRRR & $\mathrm{I}, 895.3$ & ++ \\
\hline
\end{tabular}

Abbreviations: $K$, lysine; $L$, leucine; $D$, aspartate; $R$, arginine.

95\% by high-performance liquid chromatography (Shimadzu LC-8A; Shimadzu Corporation, Kyoto, Japan), and their molecular weights were determined by mass spectrometer (LCQ Deca XP Max; Thermo Fisher Scientific, Waltham, MA, USA). Lyophilized peptide was dissolved at a concentration of $10 \mathrm{mg} / \mathrm{mL}$ in sterile water and used as a stock solution.

\section{Dynamic light scattering}

Dynamic light scattering analysis was performed on a particle size analyzer (Zetasizer Nano S; Malvern Instruments, Malvern, UK) at room temperature with appropriate viscosity and refractive index settings. SAP solution (1\%) was diluted 20 times with Milli-Q water, and each sample was tested three times to generate an intensity-based size distribution plot report.

\section{Transmission electron microscope}

Peptide solution $(10 \mu \mathrm{L})$ was evenly placed on a carboncoated copper grid. After 1 minute, the grid was rinsed with Milli-Q water to remove unattached peptide, and then stained with $2 \%$ uranyl acetate solution. After air-drying in room temperature, the sample-loaded grid was observed under a transmission electron microscope (H-7650; Hitachi Ltd., Tokyo, Japan).

\section{Scanning electron microscope}

SAP hydrogel $(0.5 \%)$ was fixed in $2.5 \%$ glutaraldehyde for 2 hours, followed by dehydration in $30 \%, 50 \%, 70 \%, 80 \%$, $90 \%$, and twice in $100 \%$ ethanol. After critical point drying with liquid $\mathrm{CO}_{2}$, the dried samples were sputter coated with gold and observed under scanning electron microscope (JSM-7500F; JEOL, Tokyo, Japan).

\section{Hep binding/retention of SAP hydrogel}

To assay the Hep binding, $50 \mu \mathrm{L}$ of SAP hydrogel $(0.5 \%$, $\mathrm{w} / \mathrm{v}$ ) was placed at the bottom of a 96 -well plate, and then incubated with $200 \mu \mathrm{L}$ of heparin sodium $(100 \mu \mathrm{g} / \mathrm{mL}$; Sigma-Aldrich Co., St Louis, MO, USA) at $37^{\circ} \mathrm{C}$ for 1 hour. After removing the supernatant and washing with phosphate-buffered saline (PBS), SAP gel was disrupted 
and extracted with trifluoroacetic acid (TFA, 1\% [v/v]) and neutralized with $\mathrm{NaOH}$. To assay the Hep retention, SAP gel (50 $\mu \mathrm{L}, 0.5 \%)$ containing Hep $(50 \mu \mathrm{g} / \mathrm{mL})$ was placed in a 96-well plate and incubated with $\mathrm{PBS}$ at $37^{\circ} \mathrm{C}$ for 14 days, and then the gel was disrupted and extracted with TFA/NaOH.

\section{Measurement of Hep by toluidine blue method}

The concentration of Hep was measured by colorimetric toluidine blue method as previously described. ${ }^{19}$ In brief, $250 \mu \mathrm{L}$ of toluidine blue $(0.005 \%$ [w/v $])$ solution was added to $250 \mu \mathrm{L}$ of Hep solution and shaken violently. Then, $500 \mu \mathrm{L}$ of hexane (Sigma-Aldrich Co.) was added to each tube and shaken violently to extract the Hep-dye complex. The absorbance of water phase at $630 \mathrm{~nm}$ was measured by ultraviolet (UV) spectrophotometer. A standard calibration curve was plotted to calculate the Hep concentration. To visualize Hep in SAP hydrogel, the gels were stained with toluidine blue solution $(0.05 \%[\mathrm{w} / \mathrm{v}])$ at room temperature for 20 minutes, washed with PBS, and observed under light microscope (IX71; Olympus Corporation, Tokyo, Japan).

\section{Circular dichroism spectroscopy}

The circular dichroism (CD) measurement of peptide $(1 \mathrm{mg} / \mathrm{mL})$ and heparin sodium $(0.1 \mathrm{mg} / \mathrm{mL})$ solution was performed at $25^{\circ} \mathrm{C}$ on an Aviv Model 400 (Aviv Biomedical Inc., Lakewood, NJ, USA) with quartz cuvette (2 mm path length). CD spectra were collected at $1 \mathrm{~nm}$ intervals and $1 \mathrm{~nm}$ bandwidths from 190 to $260 \mathrm{~nm}$ with three time scans to calculate the average. All data were corrected by subtracting the baseline and expressed as molar ellipticity $\left(\theta\left[\mathrm{deg} \cdot \mathrm{cm}^{2} \cdot \mathrm{dmol} / \mathrm{L}\right]\right)$.

\section{Fourier transform infrared spectroscopy}

Peptide and Hep samples were dissolved in Milli-Q water, and SAP-Hep complex solution was prepared by the addition of Hep $(0.25 \mathrm{mg} / \mathrm{mL})$ to peptide $(1 \mathrm{mg} / \mathrm{mL})$ solution. Fourier transform infrared (FTIR) spectra of thin films of solution between $\mathrm{KBr}$ plates were obtained on a Nicolet 5700 spectrophotometer (Thermo Electron Scientific Instruments Corp., Madison, WI, USA) from the wavelengths of 4,000 to $500 \mathrm{~cm}^{-1}$.

\section{In vitro release of HGF from SAP/Hep gel}

In vitro release of HGF (recombinant human; PeproTech, Rocky Hill, NJ, USA) from SAP gel was performed in PBS solution. In brief, HGF-loaded SAP solution was prepared by mixing of SAP ( $5 \mathrm{mg} / \mathrm{mL})$, Hep $(20 \mu \mathrm{g} / \mathrm{mL})$, and HGF
(200 ng/mL), and then the mixture was induced to form hydrogel by PBS. Approximately, $50 \mu \mathrm{L}$ of gel was placed in a 96-well plate, and $200 \mu \mathrm{L}$ of $\operatorname{PBS}(0.1 \mathrm{M}, \mathrm{pH}=7.2)$ containing $0.3 \%(\mathrm{w} / \mathrm{v})$ bovine serum albumin (BSA) was added gently and incubated at $37^{\circ} \mathrm{C}$. INS- 1 cells $\left(1 \times 10^{5}\right)$ were also cultured in HGF $(200 \mathrm{ng} / \mathrm{mL})$-loaded SAP gels $(5 \mathrm{mg} / \mathrm{mL}$, $50 \mu \mathrm{L})$ without and with Hep $(20 \mu \mathrm{g} / \mathrm{mL})$, respectively. The cell-loaded gels were allowed to release HGF in culture media (Roswell Park Memorial Institute [RPMI] 1640 with 10\% fetal bovine serum $[\mathrm{FBS}]$ ) at $37^{\circ} \mathrm{C}$. At indicated time points, the supernatant was collected and replaced with fresh release media. The concentration of HGF was measured by commercial human HGF enzyme-linked immunosorbent assay (ELISA) kit (Dakewei Biotech, Beijing, People's Republic of China) according to the manufacturer's protocol.

\section{In vitro inflammation model of $\beta$-cell}

Rat insulinoma $\beta$-cell line INS-1 was cultured in RPMI 1640 medium supplemented with 10\% FBS, $100 \mathrm{U} / \mathrm{mL}$ penicillin, $100 \mathrm{U} / \mathrm{mL}$ streptomycin, $1 \mathrm{mM}$ sodium pyruvate (Sigma-Aldrich Co.), and $50 \mu \mathrm{M} \beta$-mercaptoethanol (SigmaAldrich Co.) in an atmosphere of $5 \% \mathrm{CO}_{2}$ at $37^{\circ} \mathrm{C}$. To mimic the inflammatory condition posttransplantation, cells were stimulated with recombinant human TNF- $\alpha$ ( 5 ng/mL; PeproTech) for 7 days. For HGF treatment, cells were incubated with release media from HGF-loaded SAP gels, and the media with TNF- $\alpha$ was changed every day. In all the cell experiments, normal cultured cells without any treatment were used as control.

\section{Cell viability and apoptosis}

Cell viability was evaluated by Cell Counting Kit-8 (CCK-8; Dojindo, Kumamoto, Japan) according to the manufacturer's protocol. In brief, cells were seeded in a 96-well plate and exposed to the indicated treatment, and then CCK-8 solution was added into each well. After incubating at $37^{\circ} \mathrm{C}$ for 1.5 hours, the absorbance was measured at $450 \mathrm{~nm}$ by microplate reader (BioTek Instruments, Winooski, VT, USA). Cell apoptosis rate was determined by annexin V/propidium iodide (PI) kit (BD Biosciences, San Jose, CA, USA). After treatment, cells were resuspended in trypsin and stained with annexin V-fluorescein isothiocyanate (FITC) and PI solution for 15 minutes at room temperature. The stained cells were collected and washed with PBS and then analyzed by flow cytometer (FC500; Beckman Coulter, Inc., Brea, CA, USA).

\section{Lactate dehydrogenase release assay}

The cytotoxicity of peptides on INS-1 cells was also assessed by lactate dehydrogenase (LDH) release assay kit (Beyotime 
Institute of Biotechnology, Nantong, People's Republic of China) according to the manufacturer's instruction. Briefly, cells were cultured in SAP gel for 24 hours, and LDH working solution was then added to each well and incubated for 1 hour. The activity of LDH in the culture medium was measured by microplate reader (BioTek Instruments) at $490 \mathrm{~nm}$ wavelength.

\section{Glucose-stimulated insulin secretion test}

After treatment, cells were collected and washed with KrebsRinger bicarbonate (KRB, $\mathrm{pH}=7.2$ ) buffer containing $1 \%$ BSA. The cells were first incubated in $\mathrm{KRB}$ with $2 \mathrm{mM}$ glucose at $37^{\circ} \mathrm{C}$ for 1 hour, and then the buffer was removed and replaced with fresh $\mathrm{KRB}$ with $20 \mathrm{mM}$ glucose for 1 hour. The concentration of insulin was measured by using commercial rat insulin ELISA kit (R\&D, Systems, Inc., Minneapolis, MN, USA). Glucose stimulation index (SI) = insulin level of $20 \mathrm{mM}$ glucose/insulin level of $2 \mathrm{mM}$ glucose. After treatment, cells were collected and disrupted by sonication, and the intracellular insulin level was measured and normalized to DNA content of each sample to eliminate the influence of the cell number.

\section{Immunocytochemistry}

The cells were fixed with 4\% paraformaldehyde in PBS for 15 minutes at room temperature, and permeabilized with $0.3 \%$ Triton X-100 in PBS for 10 minutes. After blocking with 1\% BSA and $0.3 \%$ Triton X-100 in PBS for 30 minutes, the cells were incubated with diluted interleukin (IL)-1 $\beta$ antibody (ABclonal Biotechnology, Woburn, MA, USA) overnight at $4^{\circ} \mathrm{C}$, followed by incubation with tetramethylrhodamine isothiocyanate-conjugated secondary antibody (EMD Millipore, Billerica, MA, USA) at $37^{\circ} \mathrm{C}$ for 1 hour. After staining with 4',6-diamidino-2-phenylindole (Sigma-Aldrich Co.) and washing with PBS, images of stained cells were acquired by fluorescent microscope (IX71; Olympus). Quantitative analysis of micrographs was done by ImageJ software (National Institutes of Health, Bethesda, USA).

\section{Western blot analysis}

Cells were collected and lysed in cold Radioimmunoprecipitation Assay buffer, and protein concentration was measured by bicinchoninic acid (BCA) assay kit (Pierce Biotechnology, Rockford, IL, USA). Proteins were electrophorized on $12 \%$ sodium dodecyl sulfate polyacrylamide gel electrophoresis gel and then transferred to polyvinylidene fluoride (PVDF) membrane (EMD Millipore). PVDF membrane was blocked in 5\% nonfat milk buffer and then incubated with primary antibodies against Pdx-1 (Abcam, Cambridge, UK), IL-1 $\beta$ (ABclonal
Biotechnology), NFkB p65 (Santa Cruz Biotechnology Inc., Dallas, TX, USA), p-NFkB p65 (CST Co., Danvers, MA, USA), p38 (CST), p-p38 (CST), and $\beta$-actin (Santa Cruz Biotechnology Inc.) overnight at $4^{\circ} \mathrm{C}$. After washing with PBS with Tween 20, the PVDF membrane was incubated with horseradish peroxidase (HRP)-conjugated secondary antibodies (Santa Cruz Biotechnology Inc.) at $37^{\circ} \mathrm{C}$ for 1 hour. The protein band on the PVDF membrane was visualized by enhanced chemiluminescence kit (Pierce Biotechnology).

\section{In vivo syngeneic $\beta$-cell transplantation}

Adult male rats (200-250 g) were purchased from Experimental Animal Center of Sichuan University (Chengdu, People's Republic of China). Animals were housed in individual cages with controlled temperature, humidity, and 12-hour cycles of light and darkness, and fed with standard chow and tap water ad libitum. All animal experiments were approved by the Animal Care and Use Committee of Sichuan University (Chengdu, China) and were performed following the National Guide for the Care and Use of Laboratory Animals, Institute of Laboratory Animal Resources. Rats were anesthetized with $10 \%$ chloral hydrate solution, and the kidney was exposed through a small incision in the flank. Rat INS-1 $\beta$-cells $\left(1 \times 10^{7}\right.$ cells) were resuspended in $50 \mu \mathrm{L}$ of $0.5 \%$ SAP solution containing HGF (500 ng), and then injected into the space under kidney capsule. After transplantation, the kidney was replaced in the abdominal cavity, and the incision was closed with suture. For the animal experiments, rats transplanted with $\beta$-cells alone were used as control.

\section{Histological examination}

At 2 weeks after transplantation, the animals were sacrificed by giving an overdose of anesthesia. The kidney was removed and fixed in 4\% paraformaldehyde, embedded in paraffin, and sliced into $4 \mu \mathrm{m}$ thick sections. For immunohistochemistry staining, sections were deparaffinized in xylene and rehydrated in graded ethanols and antigen-retrieval with citrate buffer. After inactivation of endogenous peroxidase with $3 \% \mathrm{H}_{2} \mathrm{O}_{2}$, sections were blocked with $1 \%$ BSA and incubated with diluted primary antibodies to insulin (Santa Cruz Biotechnology Inc.), cleaved caspase-3 (Proteintech Group, Inc., Chicago, IL, USA), Pdx-1 (Abcam), IL-1 $\beta$ (ABclonal Biotechnology), CD3 (Abcam), and p-NFkB p65 (CST) overnight at $4^{\circ} \mathrm{C}$, and then stained with HRP-conjugated secondary antibodies (Dako, Glostrup, Denmark). Images of stained sections were captured by light microscope (Carl Zeiss Meditec AG, Jena, Germany) and quantified by NIH Image J software. 


\section{Statistical analysis}

Quantitative data were presented as mean \pm standard deviation and analyzed by using SPSS software, version 11.5 (SPSS Inc., Chicago, IL, USA) with one-way analysis of variance test, and a $P$-value $<0.05$ was considered as significant.

\section{Results}

\section{Characteristics of cationic SAPs}

The DLS results showed that KLD, KLD1R, and KLD2R formed nanostructures with diameters of 10-20 nm (Figure 1B), and KLD1R and KLD2R further changed to hydrogel in the presence of PBS (Figure 1C). Transmission electron microscope results showed that KLD, KLD1R, and KLD2R self-assembled into nanofibers in aqueous solution, but KLD3R did not form nanostructures (Figure 1D). Scanning electron microscope results also showed that KLD1R and KLD2R gel had cross-linked nanofiber structure similar to KLD (Figure 1E). KLD3R was excluded in the following experiments because no nanostructure and gel was formed. CCK-8 and LDH results showed that KLD1R and KLD2R had no influence on the viability of INS-1 cells, and the insulin secretion and IL-1 $\beta$ expression in $\beta$-cells were not affected (Figure S1).

\section{Enhanced Hep-binding affinity of SAPs}

Compared to KLD gel, KLD1R and KLD2R gel showed significantly increased absorption and long-term retention for Hep. KLD2R showed higher Hep-binding (Figure 2A) affinity and longer retention (Figure $2 \mathrm{~B}$ ) compared to KLD1R. Toluidine blue staining results also showed that KLD2R gel bound greater amounts of Hep than the other gels (Figure 2C). CD results revealed that KLD, KLD1R, and KLD2R had typical $\beta$-sheet secondary structure, and the addition of Hep caused the shift of CD spectra (Figure 2D). FTIR results also showed Hep induced the shift of peaks at $3,433 \mathrm{~cm}^{-1}\left(\mathrm{O}-\mathrm{H}\right.$ stretch), $1,678 \mathrm{~cm}^{-1}$ (amide I), 1,543 $\mathrm{cm}^{-1}$ (amide II), and 1,459 $\mathrm{cm}^{-1}(\mathrm{C}-\mathrm{H}$ bend) in the FTIR spectra of KLD1R and KLD2R. Meanwhile, the characteristic peaks of Hep at $1,236 \mathrm{~cm}^{-1}(\mathrm{~S}=\mathrm{O}$ stretch), 1,027 cm-1 (C-O stretch), and 940-891 cm-1 were observed in the FTIR spectra of KLD1R/Hep and KLD2R/ Hep gels (Figure 2E).

\section{Sustained release of HGF by cationic SAP/Hep gel}

Compared to KLD, KLD1R and KLD2R bound higher amounts of HGF (Figure 3A). The addition of Hep increased the HGF-binding property of SAP gel, but there was no significant difference between the binding properties of KLD1R and KLD2R (Figure 3B). In vitro release results showed $80 \%$ of HGF was released from KLD gel within 24 hours, while $40 \%-60 \%$ of HGF was released from KLD1R and KLD2R gel at 48 hours (Figure 3C). KLD2R/ Hep gel showed slowest release rate, and $\sim 20 \%$ of HGF was released for 7 days (Figure 3D). The cell-loaded KLD2R/ Hep gels also showed prolonged release of HGF for 5 days (Figure 3E and F), which was similar to that of SAP/Hep gels without cells. KLD1R was excluded in the following experiments because KLD2R demonstrated slower release rate compared to KLD1R.

\section{Effect of HGF-loaded SAP/Hep gel on $\beta$-cell survival}

In vitro CCK-8 and fluorescein diacetate/PI results showed that $\beta$-cell death was reduced by TNF- $\alpha$ compared to the control ( $\beta$-cells alone) (Figure 4A-D). HGF-loaded KLD (KLD-HGF) failed to protect $\beta$-cells from TNF- $\alpha$ injury, while HGF-loaded KLD2R/Hep (KLD2R/Hep-HGF) significantly promoted $\beta$-cell viability and reduced $\beta$-cell death induced by TNF- $\alpha$ (Figure 4B-D). In vivo results showed that KLD2R/Hep-HGF group had a larger number of insulinpositive $\beta$-cells compared to the control and KLD-HGF groups (Figure 4E and F).

\section{Effect of HGF-loaded SAP/Hep gel on $\beta$-cell apoptosis}

In vitro flow cytometry and Hoechst staining results showed that TNF- $\alpha$ promoted $\beta$-cell apoptosis when compared to control ( $\beta$-cells alone), while KLD2R/Hep-HGF reduced $\beta$-cell apoptosis induced by TNF- $\alpha$, and its apoptosis rate was lower than the other groups treated with TNF- $\alpha$ (Figure 5A-C). In vivo results showed that high level of cleaved caspase- 3 was expressed in $\beta$-cells of control group, but its expression was significantly reduced in KLD2R/HepHGF group (Figure 5D and E).

\section{Effect of HGF-loaded SAP/Hep gel on $\beta$-cell function}

TNF- $\alpha$ inhibited insulin secretion and Pdx-1 expression in $\beta$-cells, and KLD-HGF did not reverse the $\beta$-cell injury induced by TNF- $\alpha$ (Figure 6A-D). In contrast, KLD2R/ Hep-HGF significantly promoted insulin secretion and $\mathrm{Pdx}-1$ expression of $\beta$-cells under TNF- $\alpha$ injury. In vivo results showed higher Pdx-1 expression (Figure 6E and G) and insulin secretion (Figure 6F) in $\beta$-cell of KLD2R/Hep-HGF group compared to the other groups. 
A
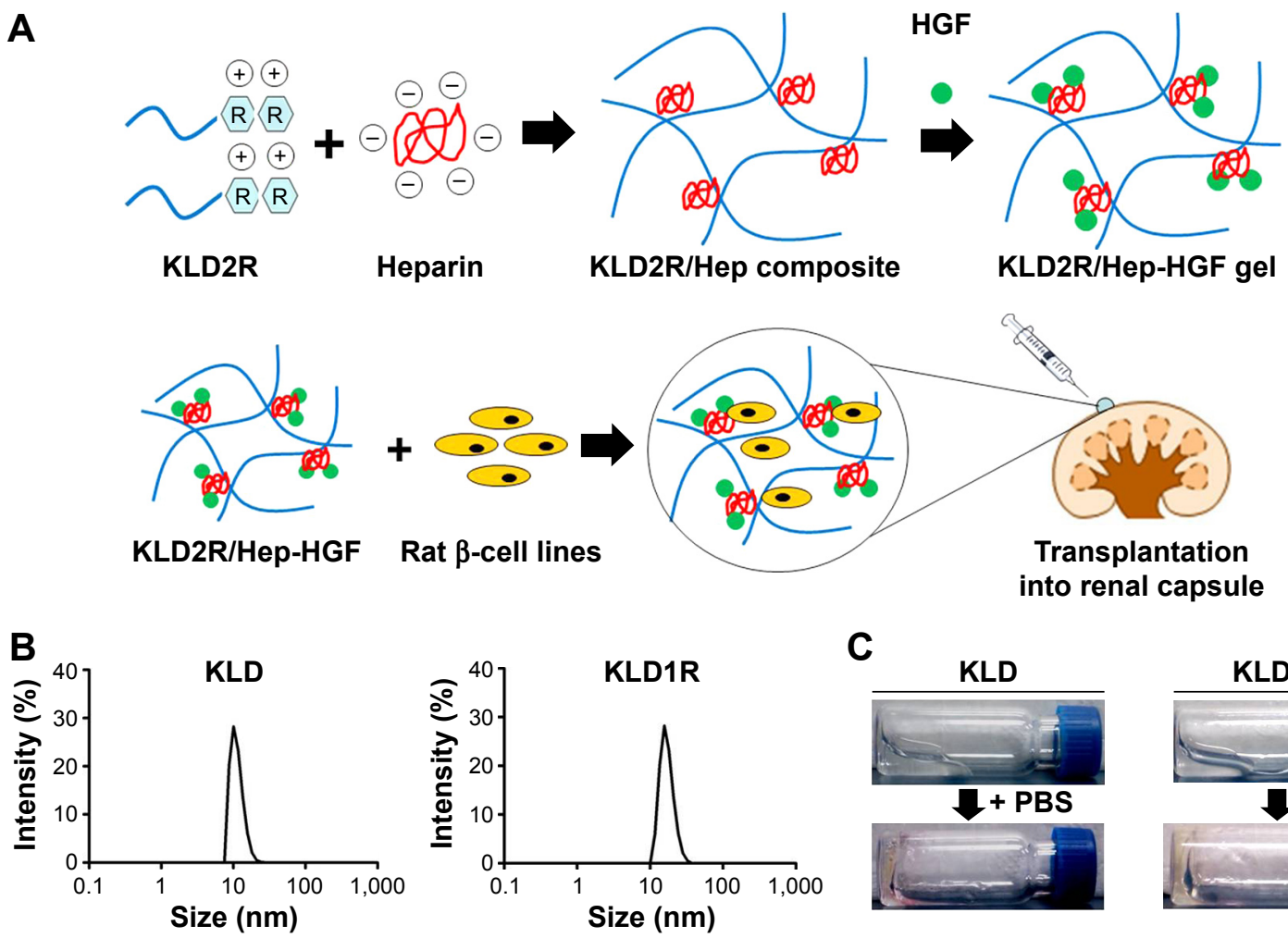

C
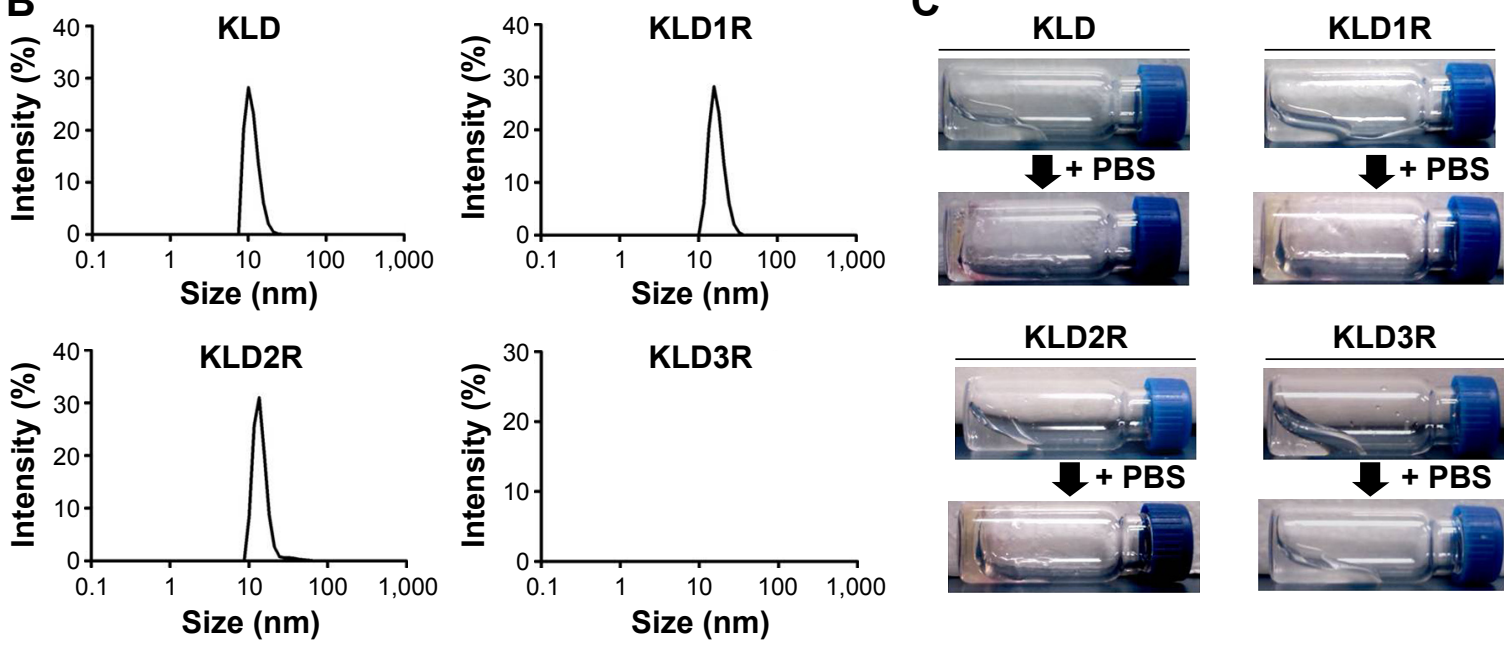

D
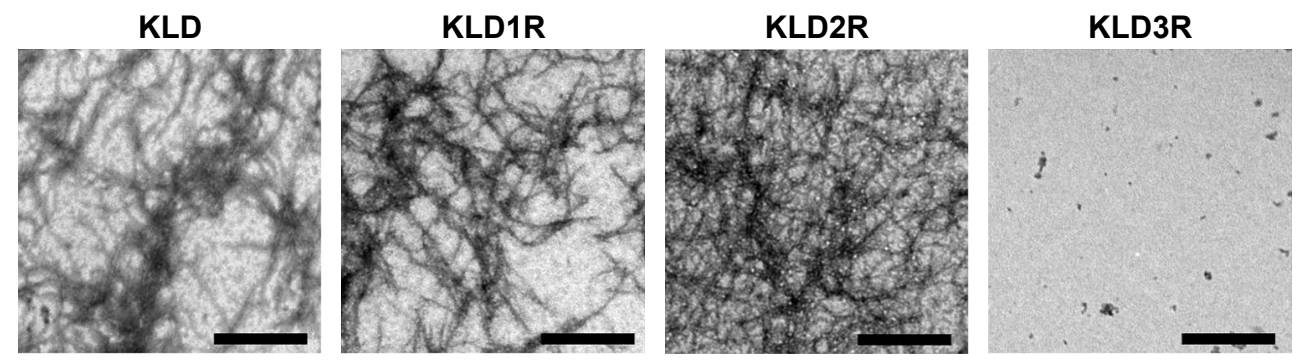

E

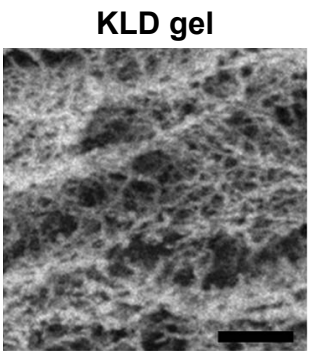

KLD1R gel
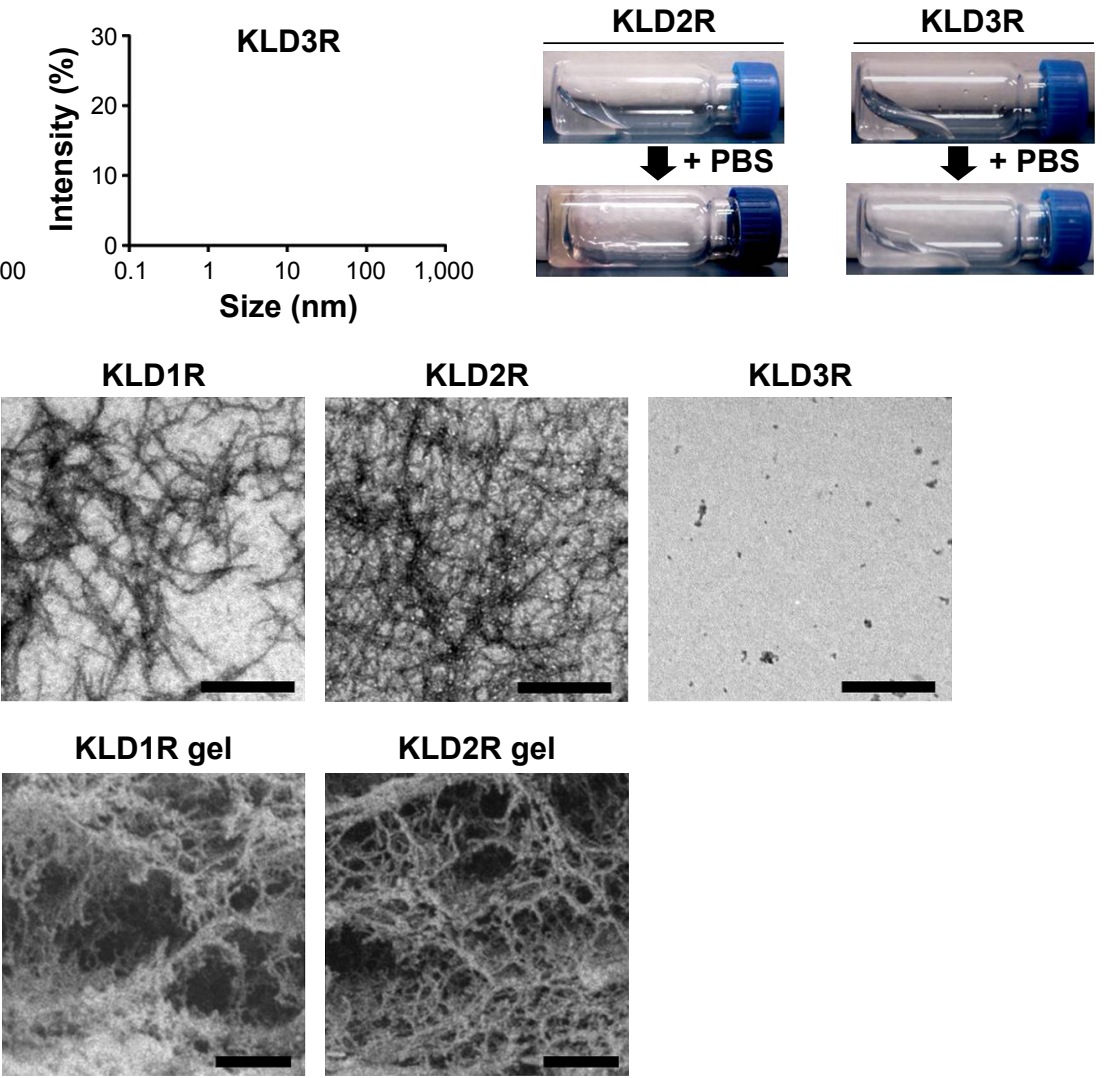

KLD2R gel

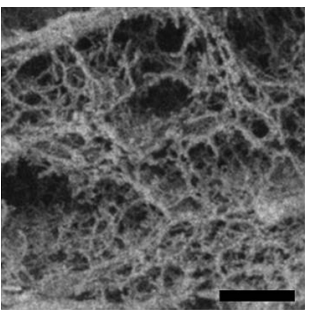

Figure I Design and characterization of cationic SAPs.

Notes: (A) Fabrication of HGF-loaded cationic SAP/heparin (SAP/Hep-HGF) gel for $\beta$-cell transplantation. (B) Determination of the diameter of SAP nanofibers by DLS. (C) Evaluation of the gel formation of SAPs $(5 \mathrm{mg} / \mathrm{mL})$. (D) TEM micrographs of SAP solution $(0.5 \mathrm{mg} / \mathrm{mL})$. (E) SEM micrographs of SAP hydrogel (5 mg/mL). The scale bar is $500 \mathrm{~nm}(\mathbf{D})$ and I $\mu \mathrm{m}(\mathbf{E})$, respectively. The magnification is $8,000 \times(\mathbf{D})$ and $10,000 \times(\mathbf{E})$, respectively.

Abbreviations: K, lysine; L, leucine; D, aspartate; R, arginine; SAP, self-assembling peptide; HGF, hepatocyte growth factor; DLS, dynamic light scattering; TEM, transmission electron microscope; SEM, scanning electron microscope; PBS, phosphate-buffered saline. 
A SAP gel + Hep Hep binding

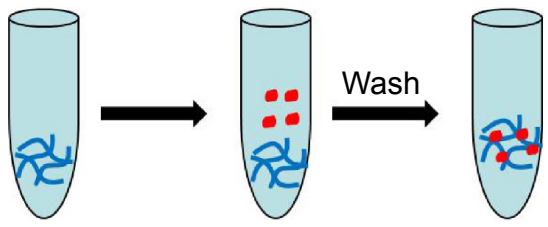

Heparin binding to gel

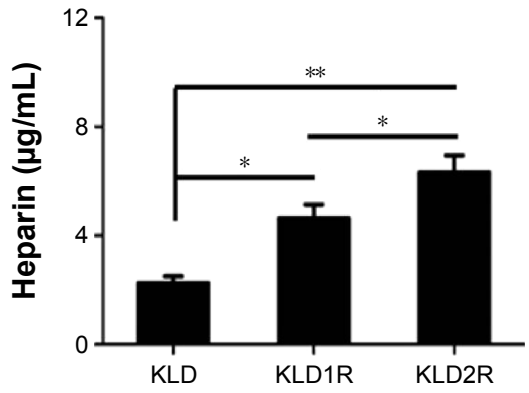

C KLD without Hep

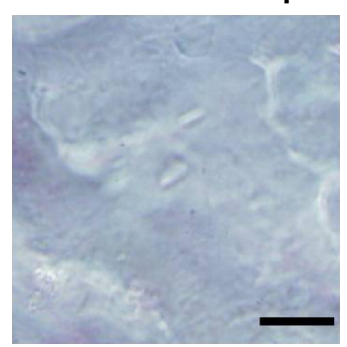

Hep binds to KLD

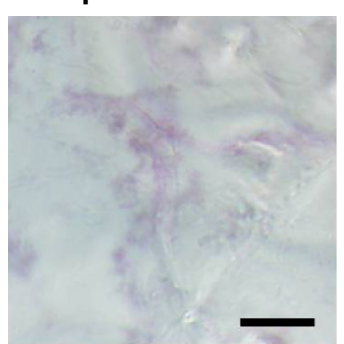

Hep binds to KLD1R

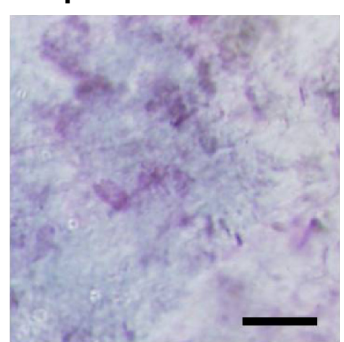

Hep binds to KLD2R
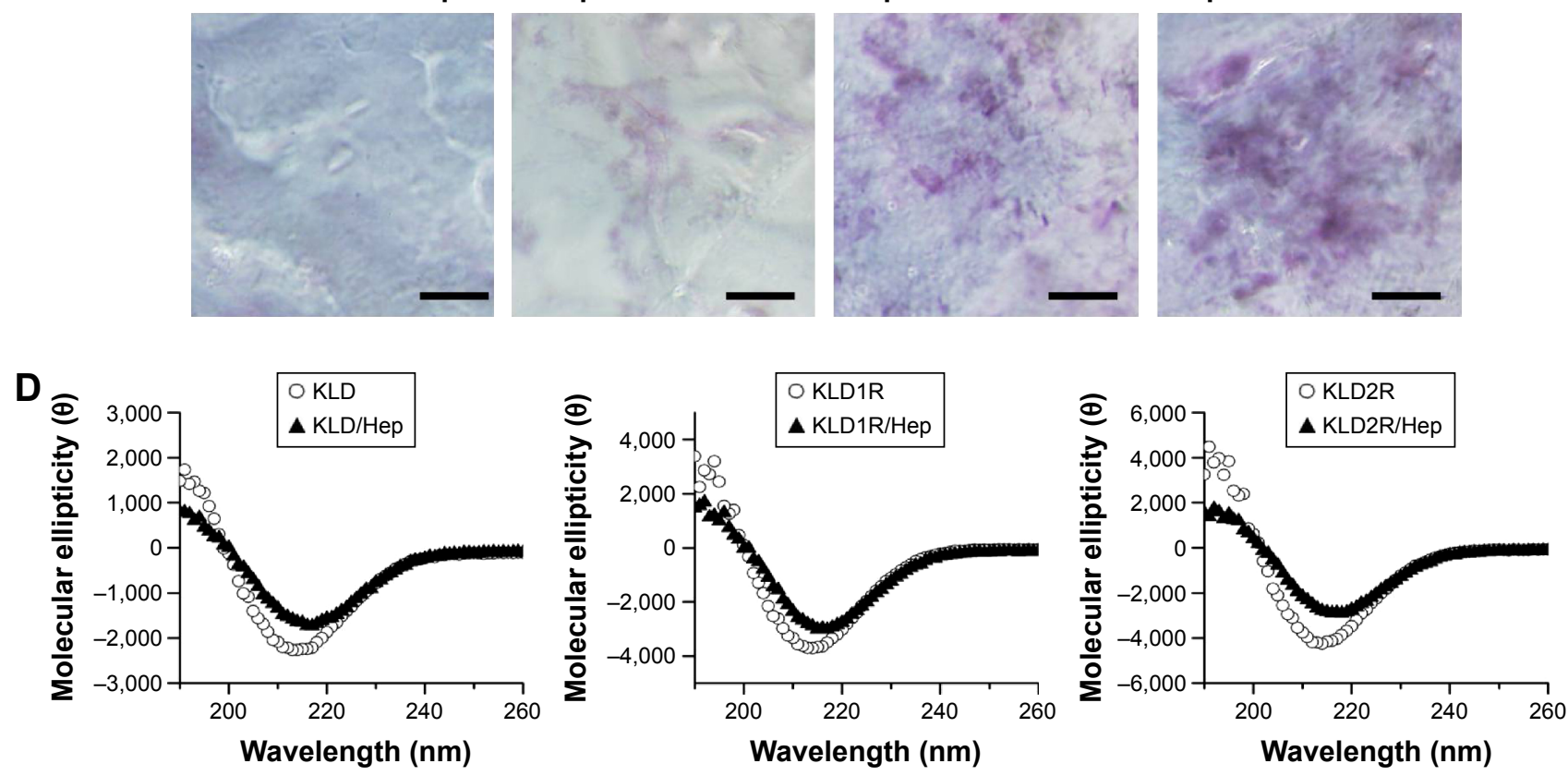

$\mathbf{E}$
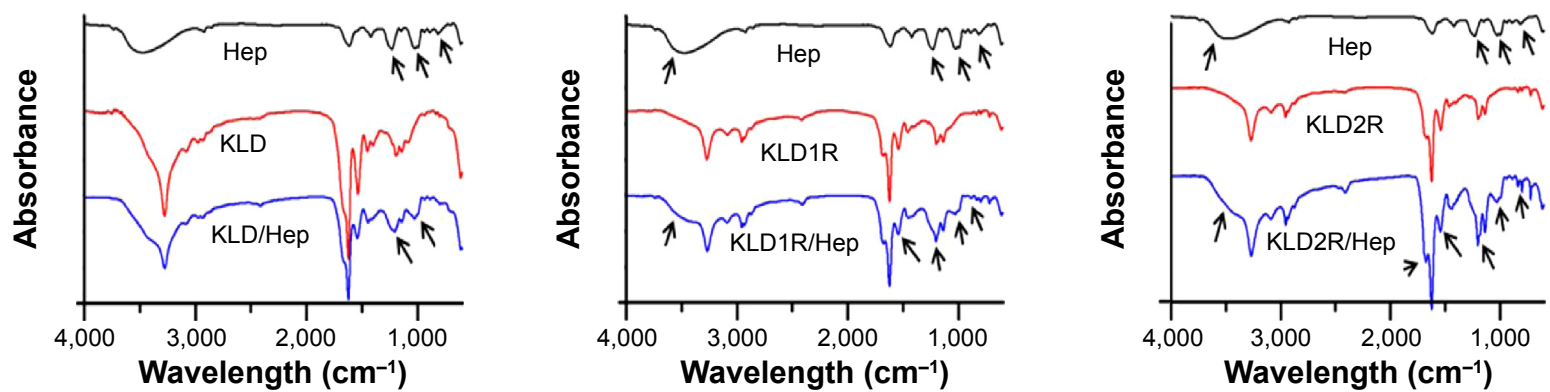

Figure 2 Effect of cationic SAPs on Hep binding and retention.

Notes: (A, B) Determination of Hep binding and retention in SAP gels by toluidine blue method. (C) Toluidine blue staining of Hep bound to SAP gels (scale bar $=200$ $\mu \mathrm{m})$. (D) Circular dichroism spectra of SAP and SAP/Hep solution. (E) FTIR spectra of Hep, SAP, and SAP/Hep solution. Data are mean \pm SD. $* P<0.05$; $* * P<0.01$. I00X magnification (C). Arrows indicate the shift of SAP peaks induced by Hep.

Abbreviations: K, lysine; L, leucine; D, aspartate; R, arginine; Hep, heparin; SAP, self-assembling peptide; FTIR, Fourier transform infrared. 


\section{A}

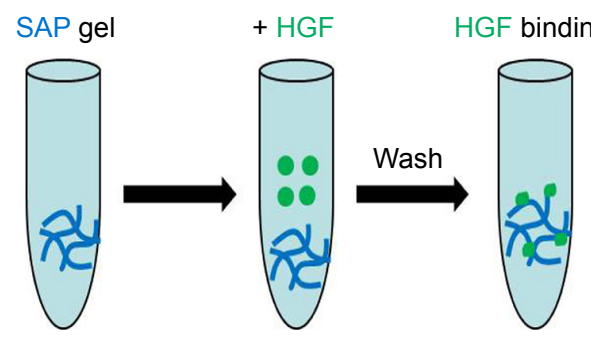

HGF binding to SAP gel

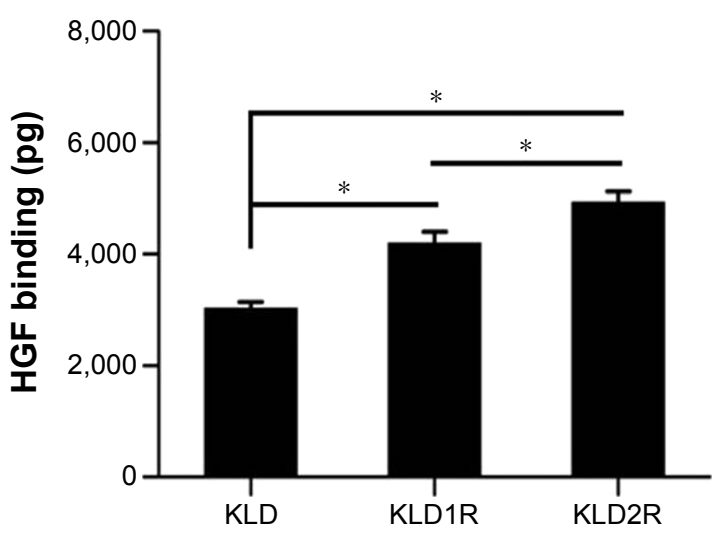

C

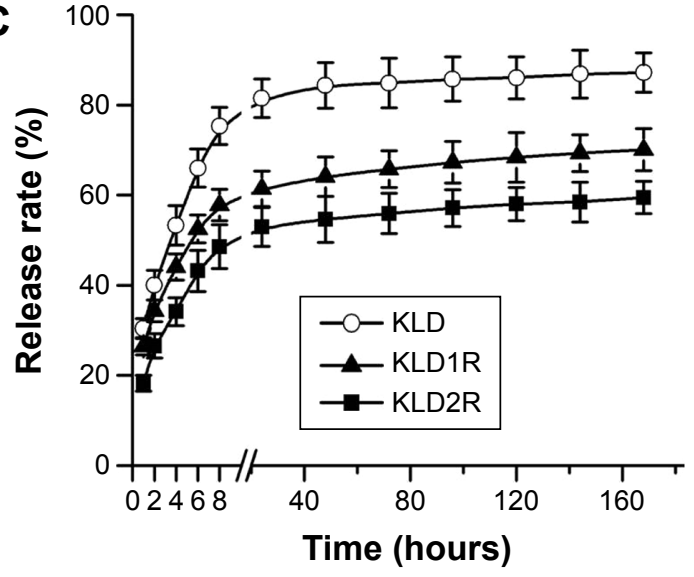

E

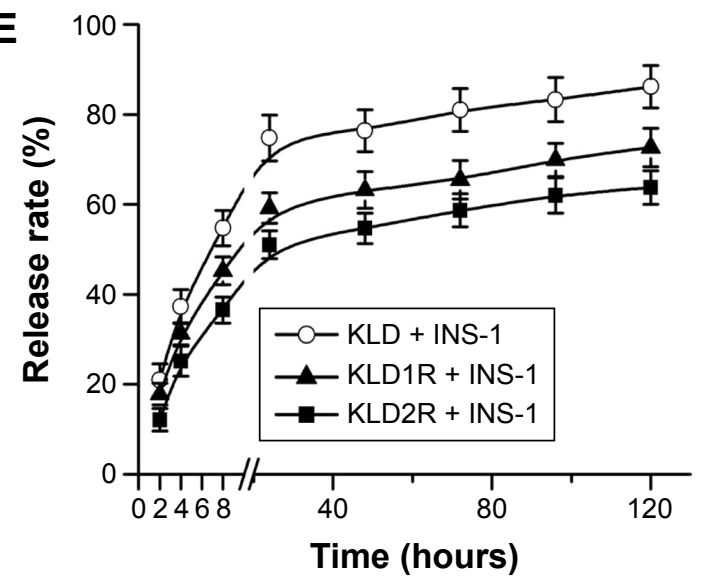

B

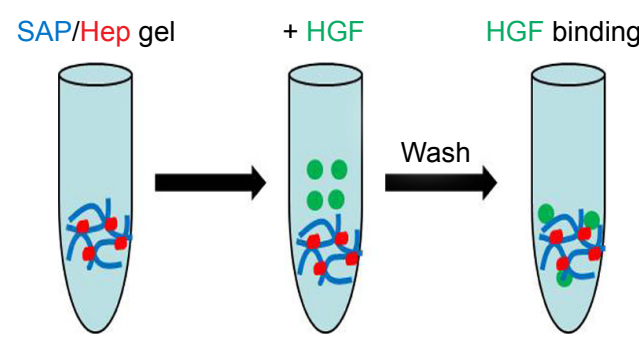

HGF binding to SAP/Hep gel

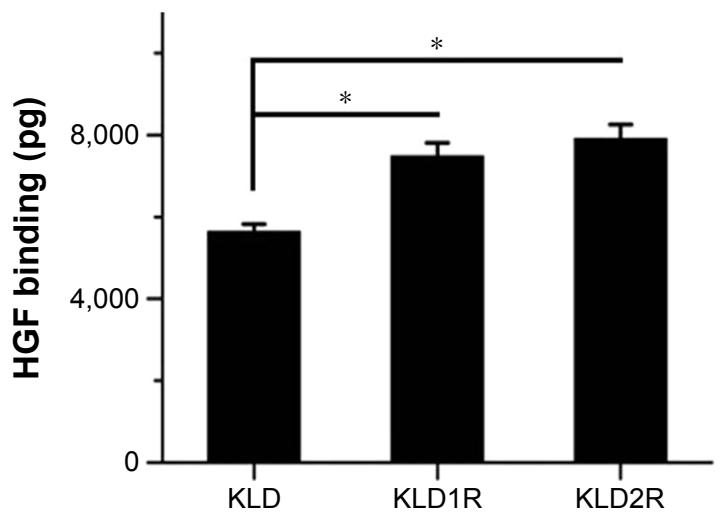

D

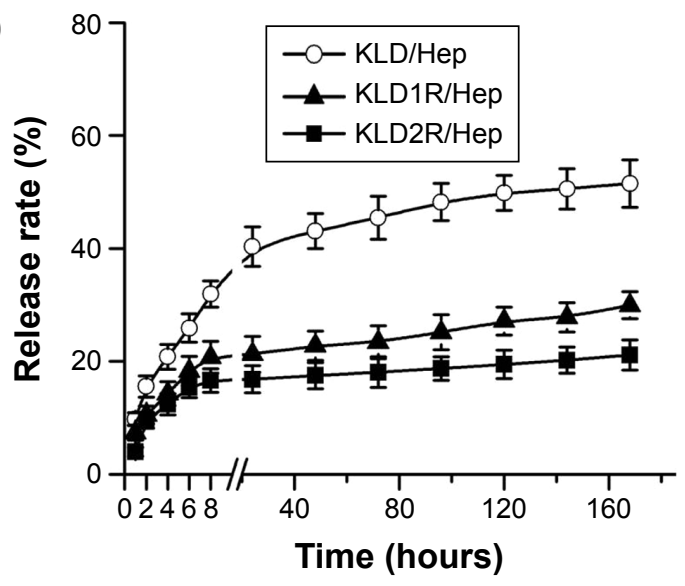

$\mathbf{F}$

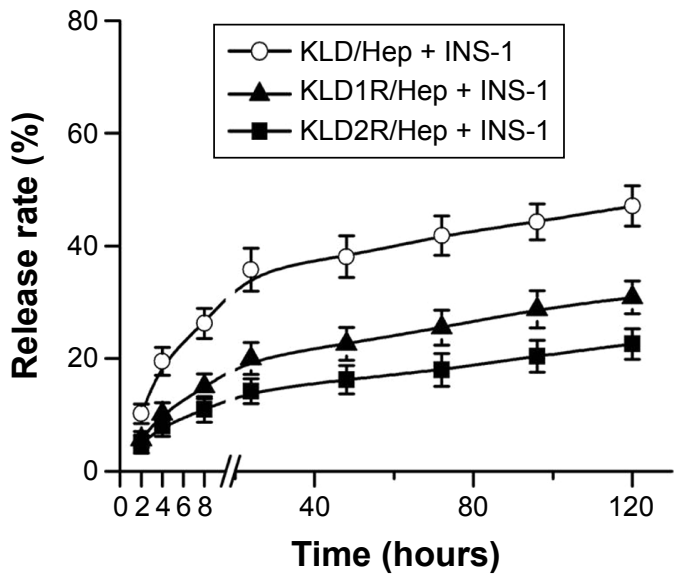

Figure 3 Effect of cationic SAP/Hep gel on HGF binding and release.

Notes: (A, B) Determination of HGF binding to SAP and SAP/Hep gels by ELISA. (C, D) In vitro release of HGF from SAP and SAP/Hep gels in PBS. (E, F) In vitro release of HGF from cells-loaded SAP and SAP/Hep gels in culture media. Data are mean $\pm \mathrm{SD}$. $* P<0.05$.

Abbreviations: K, lysine; L, leucine; D, aspartate; R, arginine; SAP, self-assembling peptide; Hep, heparin; HGF, hepatocyte growth factor; ELISA, enzyme-linked immunosorbent assay; PBS, phosphate-buffered saline. 
A

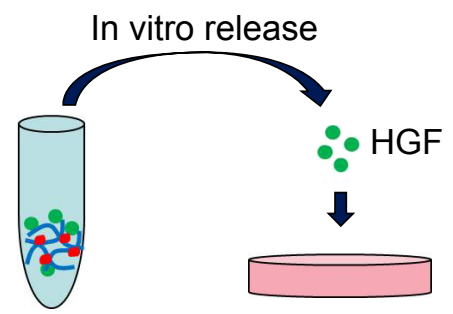

SAP/Hep-HGF Gel cell treatment

C

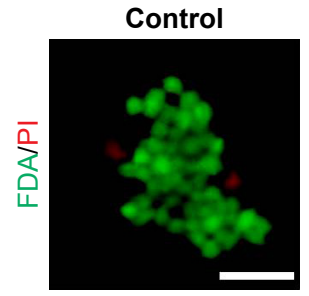

TNF

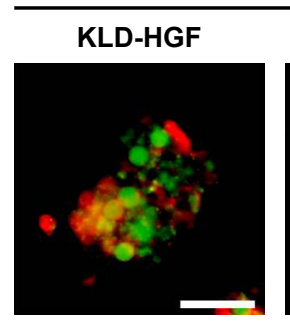

E

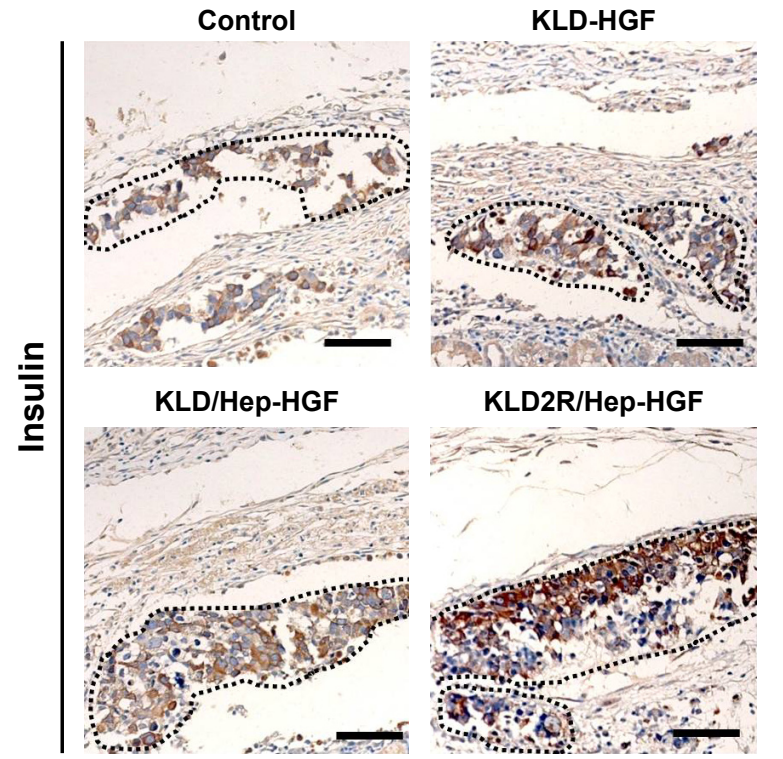

B $\quad \beta$-cell viability

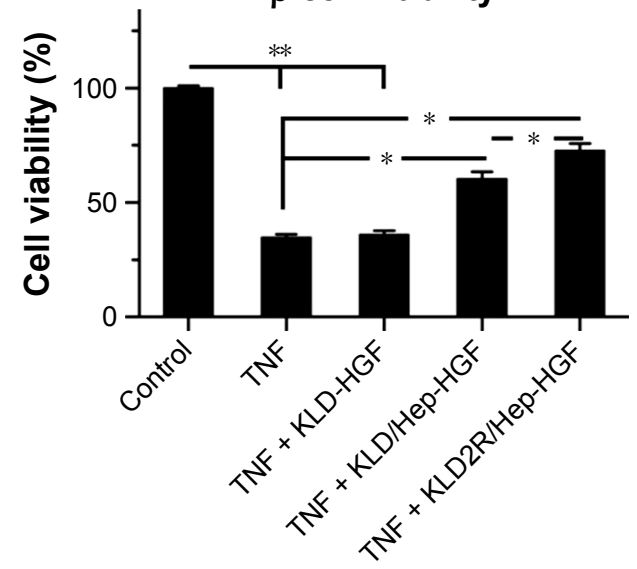

D

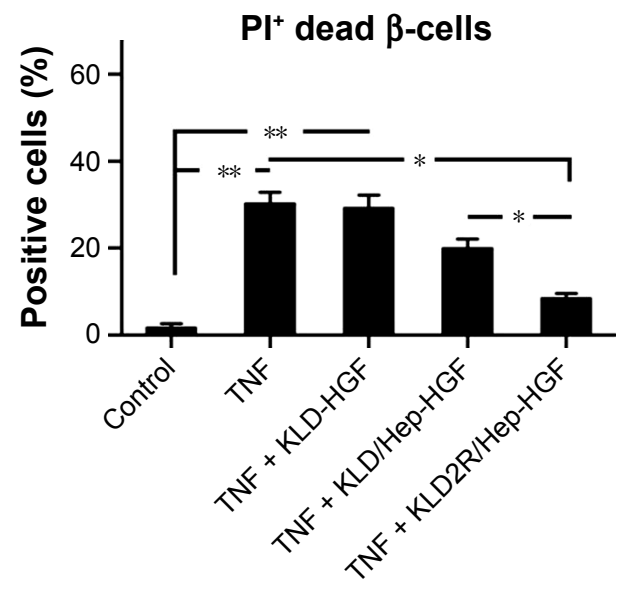

$\mathbf{F}$

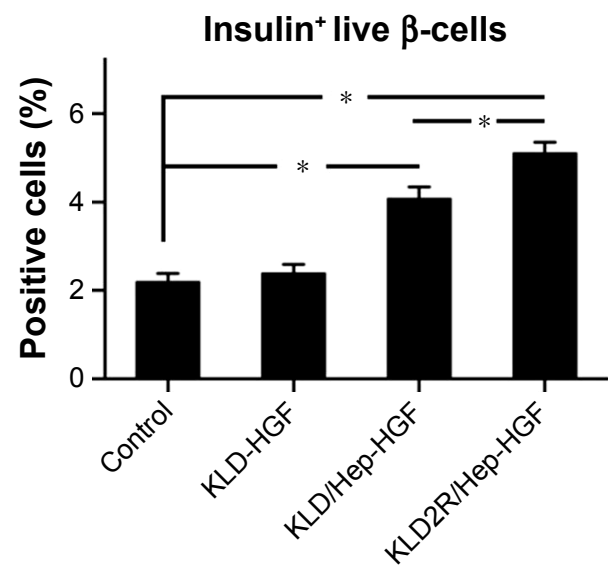

Figure 4 Effect of HGF-loaded SAP/Hep gel on $\beta$-cell survival.

Notes: (A) Schematic map of $\beta$-cells treated with release media from SAP/Hep gel. (B) Evaluation of $\beta$-cell viability in vitro by CCK-8 assay. (C, D) FDA/PI fluorescent staining of INS-I $\beta$-cell in vitro, FDA (green) and PI (red) indicated live and dead cells, respectively (scale bar $=50 \mu \mathrm{m}$ ). (E, F) Evaluation of insulin-positive live $\beta$-cells in vivo by IHC staining (scale bar $=50 \mu \mathrm{m}$ ). Data are mean $\pm \mathrm{SD}$. $* P<0.05 ; * * P<0.01$.

Abbreviations: K, lysine; L, leucine; D, aspartate; R, arginine; SAP, self-assembling peptide; Hep, heparin; FDA, fluorescein diacetate; PI, propidium iodide; IHC, immunohistochemistry; TNF, tumor necrosis factor; HGF, hepatocyte growth factor; CCK, cell counting kit. 
A
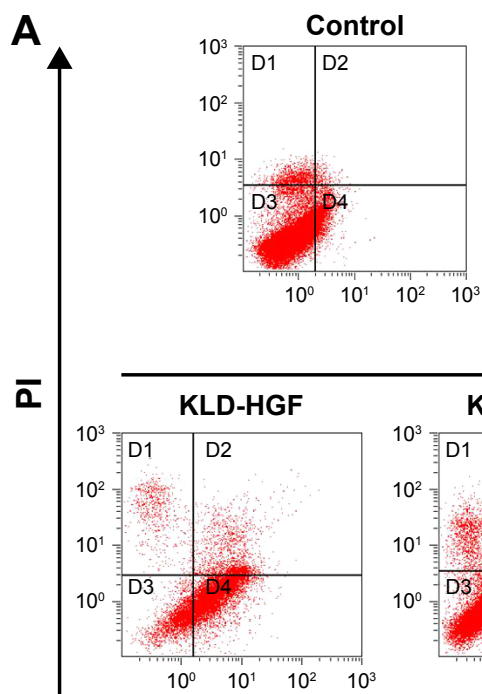

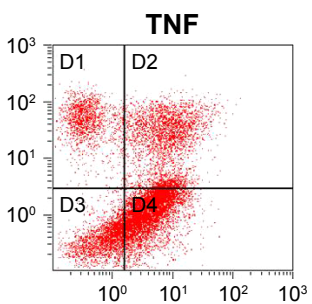

TNF

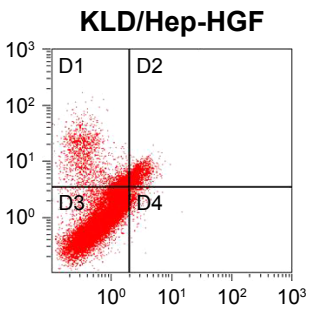

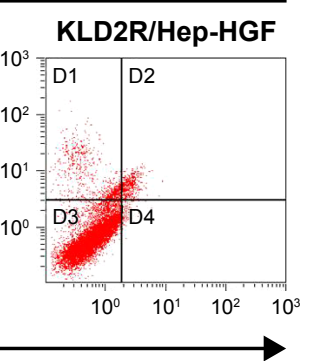

Annexin V
B

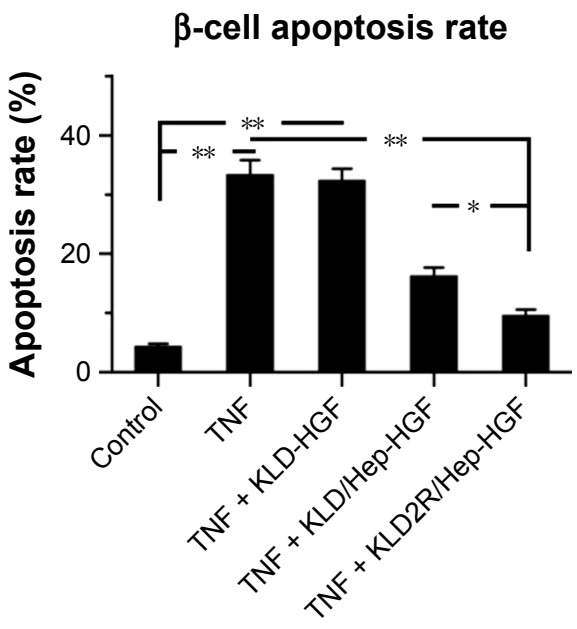

C TNF
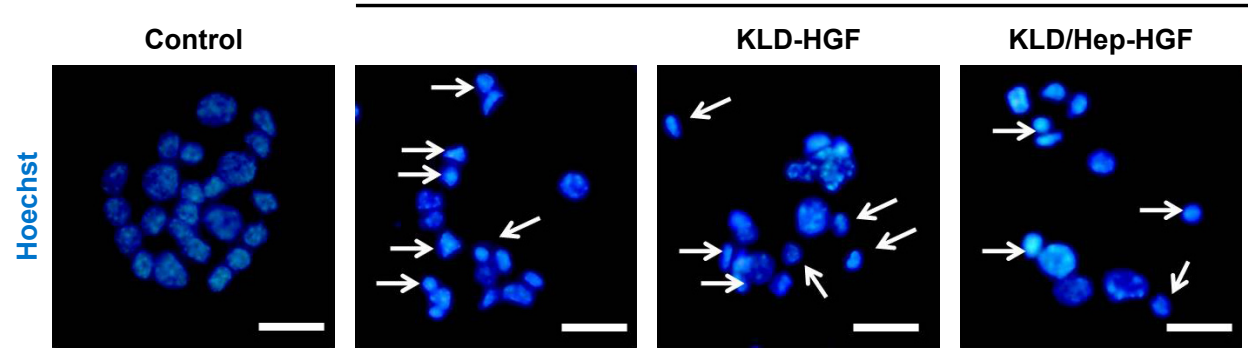

KLD2R/Hep-HGF

D

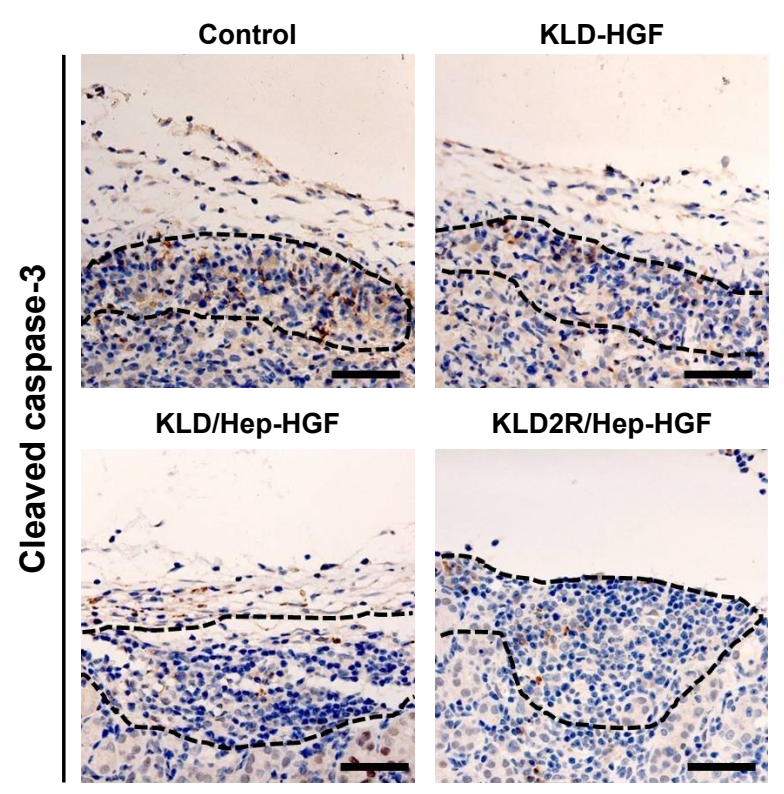

E

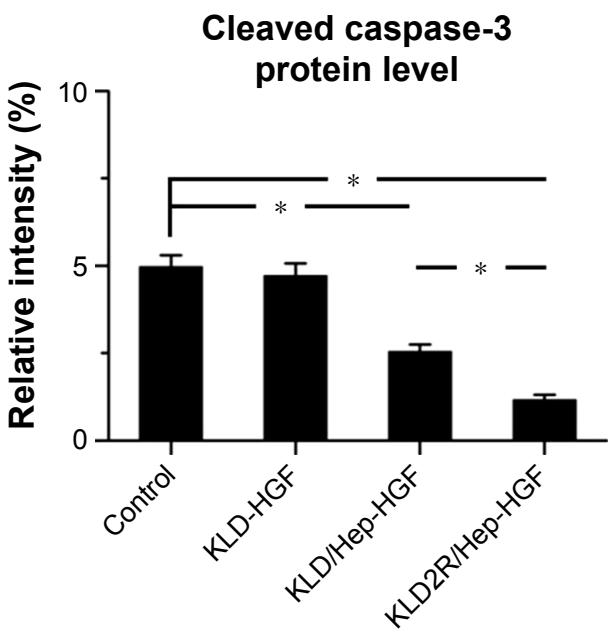

Figure 5 Effect of HGF-loaded SAP/Hep gel on $\beta$-cell apoptosis.

Notes: (A) Evaluation of $\beta$-cell apoptosis by flow cytometry (FCM). (B) Percentage of cell apoptosis determined by FCM. (C) Hoechst fluorescent staining indicated apoptosis in cells (scale bar $=25 \mu \mathrm{m})$. (D, E) IHC staining for cleaved caspase-3 (Cas-3) in $\beta$-cells in vivo (scale bar $=50 \mu \mathrm{m})$. Data are mean \pm SD. $* P<0.05$; $* * P<0.01$. $400 \times$ magnification (C), $200 \times(\mathbf{D})$. Arrows indicate apoptotic and dead cells.

Abbreviations: K, lysine; L, leucine; D, aspartate; R, arginine; HGF, hepatocyte growth factor; SAP, self-assembling peptide; Hep, heparin; IHC, immunohistochemistry; $\mathrm{PI}$, propidium iodide; TNF, tumor necrosis factor. 
A

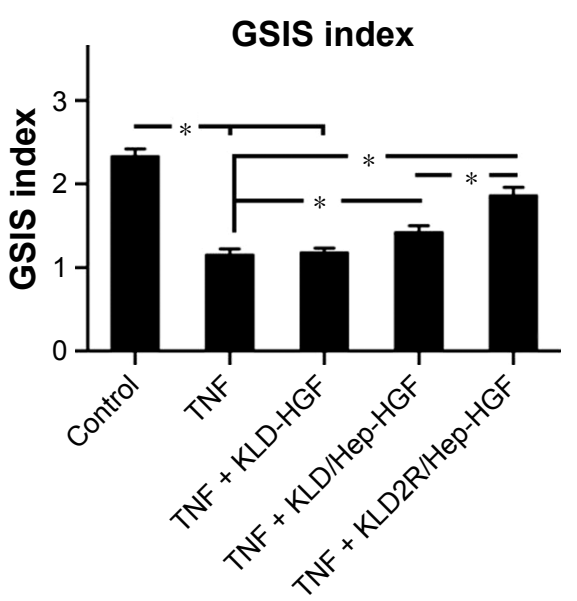

C

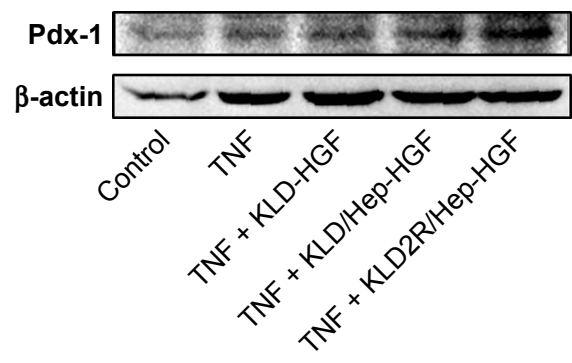

E

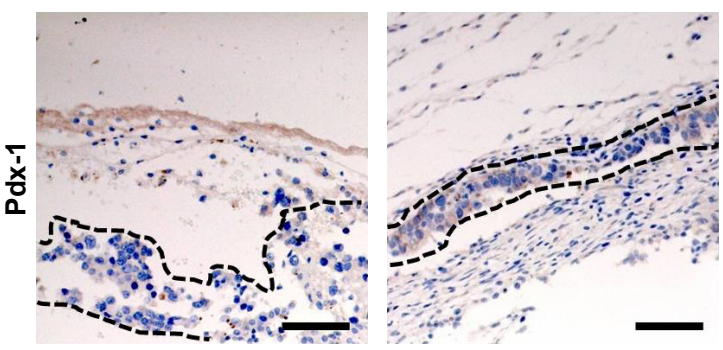

$\mathbf{F}$

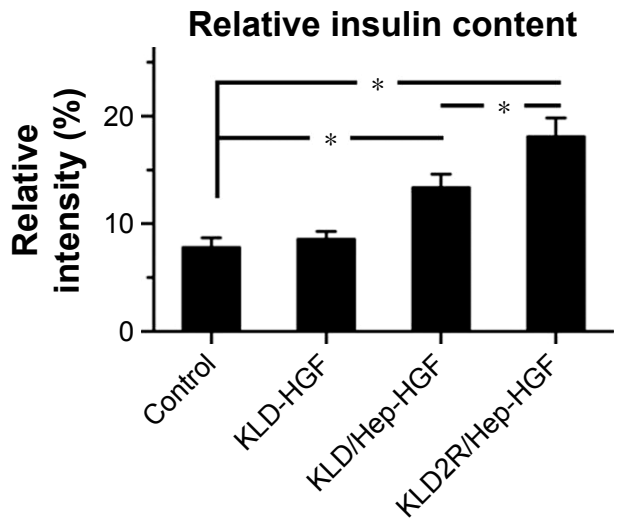

B

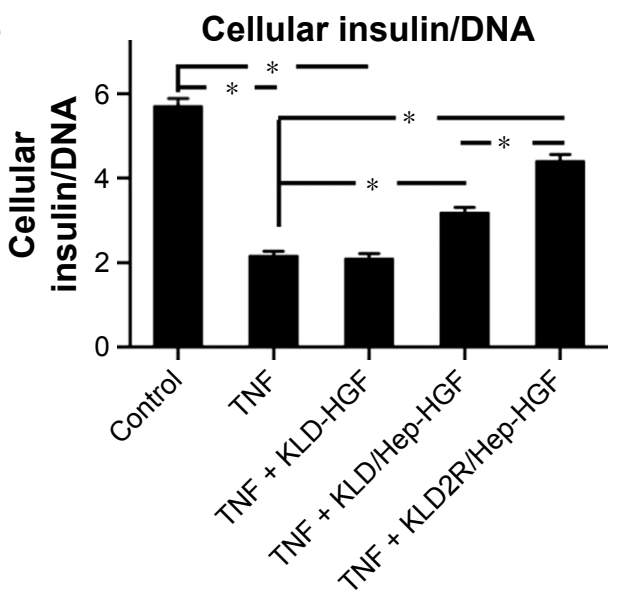

D

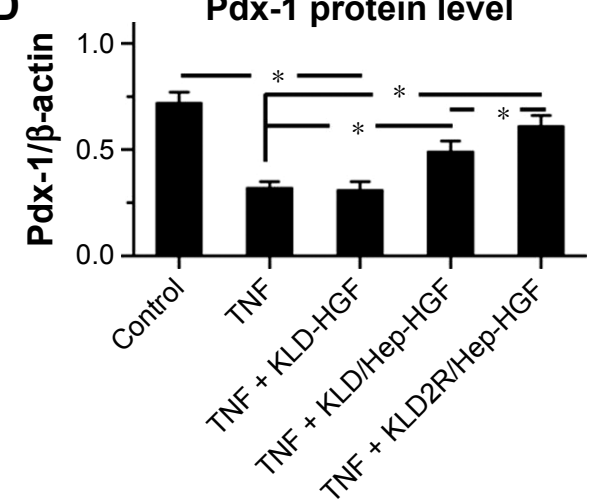

KLD/Hep-HGF

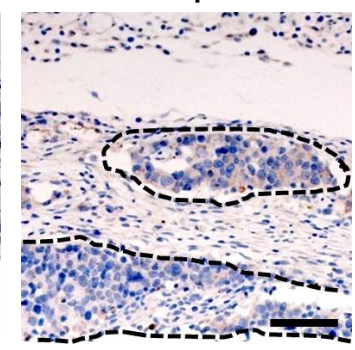

KLD2R/Hep-HGF

G

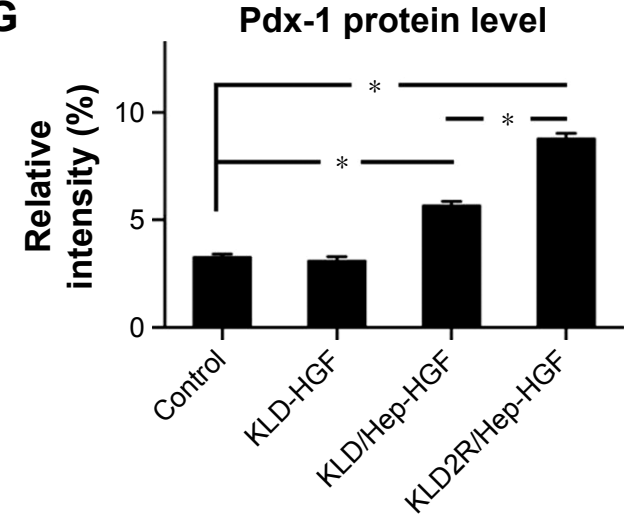

Figure 6 Effect of HGF-loaded SAP/Hep gel on $\beta$-cell function.

Notes: (A) Evaluation of glucose stimulation index by GSIS test. (B) Determination of intracellular insulin level of $\beta$-cell in vitro. (C, D) Western blot and quantitative analysis of $\mathrm{Pdx}-\mathrm{I}$ protein level in $\beta$-cell in vitro. (E) IHC staining and (G) quantitative analysis of $\mathrm{Pdx}$-I protein level in vivo (scale bar $=50 \mu \mathrm{m})$. (F) Relative insulin secretion by $\beta$-cells in vivo as determined by IHC staining. Data are mean $\pm S D$. $* P<0.05 .200 \times$ magnification.

Abbreviations: K, lysine; L, leucine; D, aspartate; R, arginine; HGF, hepatocyte growth factor; SAP, self-assembling peptide; Hep, heparin; GSIS, glucose-stimulated insulin secretion test; IHC, immunohistochemistry; TNF, tumor necrosis factor. 
A

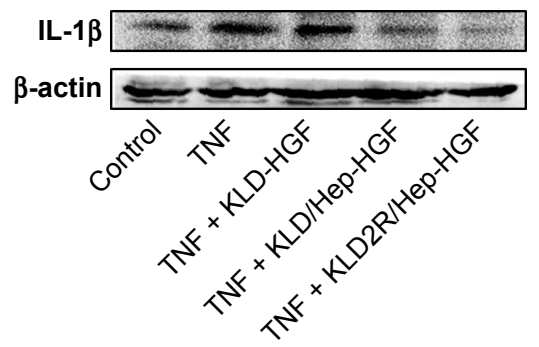

B

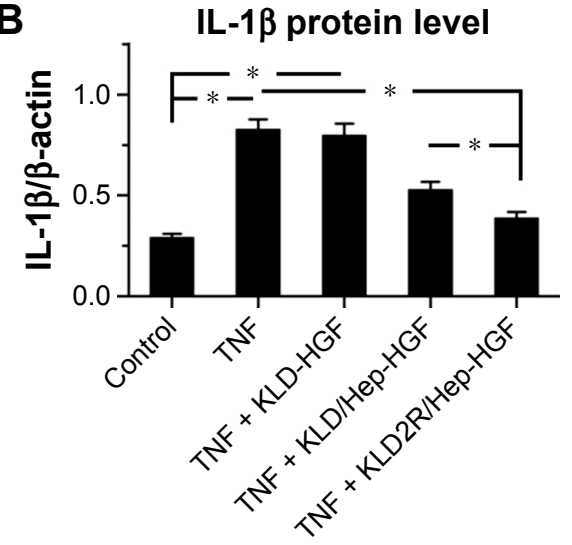

C

TNF
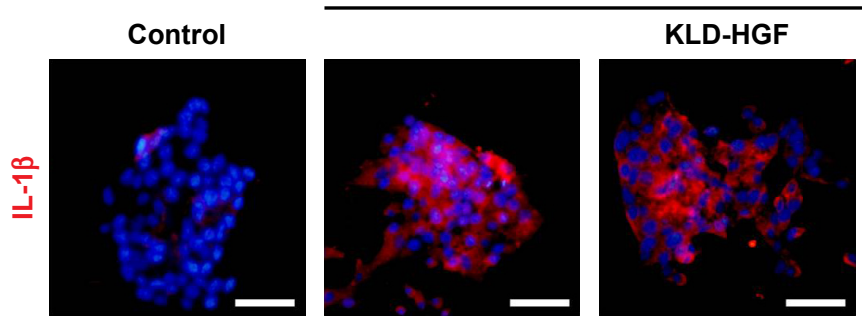

KLD/Hep-HGF

KLD2R/Hep-HGF

D

Control

KLD-HGF
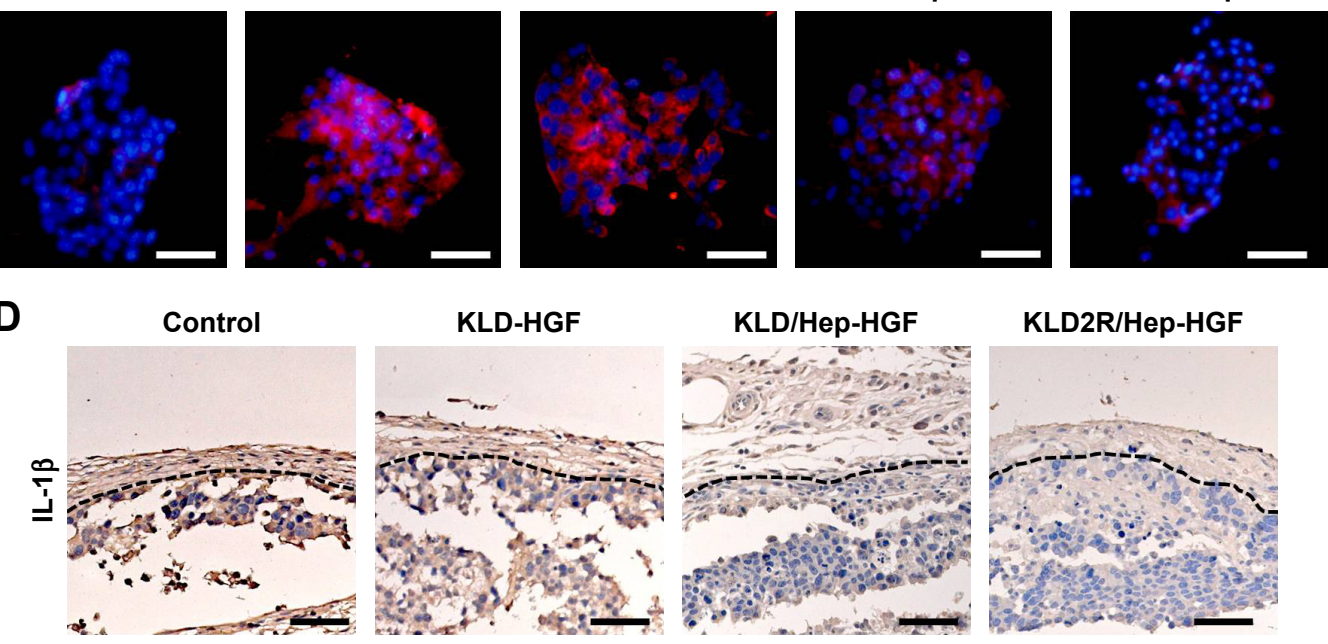

KLD2R/Hep-HGF
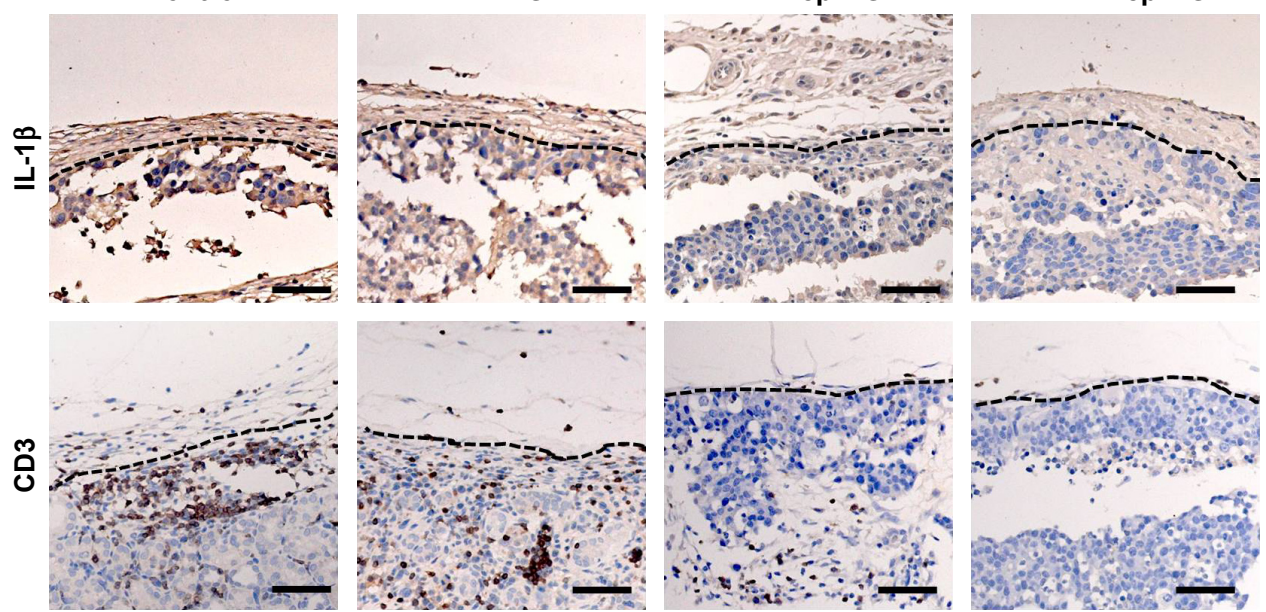

E

IL-1 $\beta$ protein level

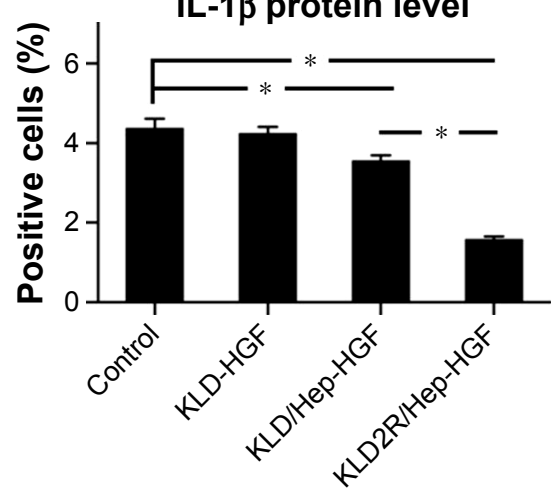

F

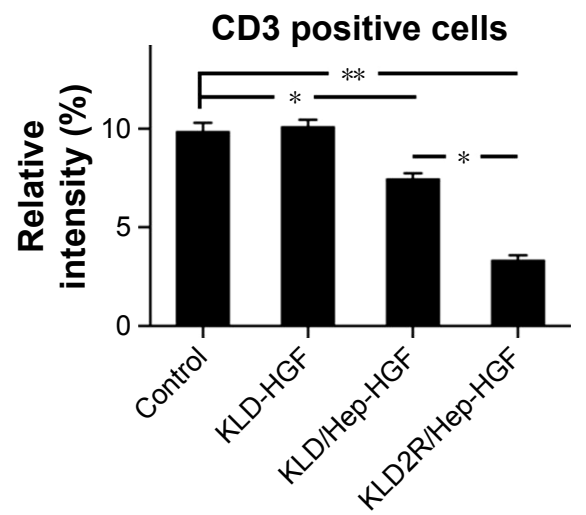

Figure 7 Effect of HGF-loaded SAP/Hep gel on inflammation of $\beta$-cell.

Notes: (A, B) Western blot and quantitative analysis of IL-I $\beta$ protein level in vitro. (C) Immunofluorescence (IF) staining for IL-I $\beta$ in vitro (scale bar $=50 \mu$ m). (D) IHC staining for IL-I $\beta$ and CD3 in vivo (scale bar $=50 \mu \mathrm{m}$ ). Quantitative analysis of (E) IL-I $\beta$ protein and $(\mathbf{F}) \mathrm{CD}^{+} \mathrm{T}$ lymphocytes in vivo as determined by IHC staining. Data are mean $\pm S D$. $* P<0.05 ; * * P<0.01$. 200 $\times$ magnification.

Abbreviations: K, lysine; L, leucine; D, aspartate; R, arginine; HGF, hepatocyte growth factor; SAP, self-assembling peptide; Hep, heparin; IHC, immunohistochemistry; TNF, tumor necrosis factor; IL, interleukin. 


\section{Effect of SAP/Hep-HGF hydrogel on inflammation}

TNF- $\alpha$ led to the increase of inflammatory cytokine IL-1 $\beta$ expression (Figure $7 \mathrm{~A}-\mathrm{C}$ ), and induced the activation of $\mathrm{NF} \kappa \mathrm{B}$ and $\mathrm{p} 38$ pathways in $\beta$-cells (Figure $8 \mathrm{~A}$ and $\mathrm{B}$ ). In contrast, KLD2R/Hep-HGF reduced IL-1 $\beta$ and p-NF $\kappa B / p-I \kappa B \alpha$ levels significantly compared to KLD-HGF and KLD/HepHGF groups. KLD2R/Hep-HGF also inhibited the IL-1 $\beta$ expression and the infiltration of $\mathrm{CD}^{+} \mathrm{T}$ lymphocytes (Figure 7D-F), and p-NFאB level (Figure 8C and D) in the transplanted $\beta$-cells was reduced in vivo.

A

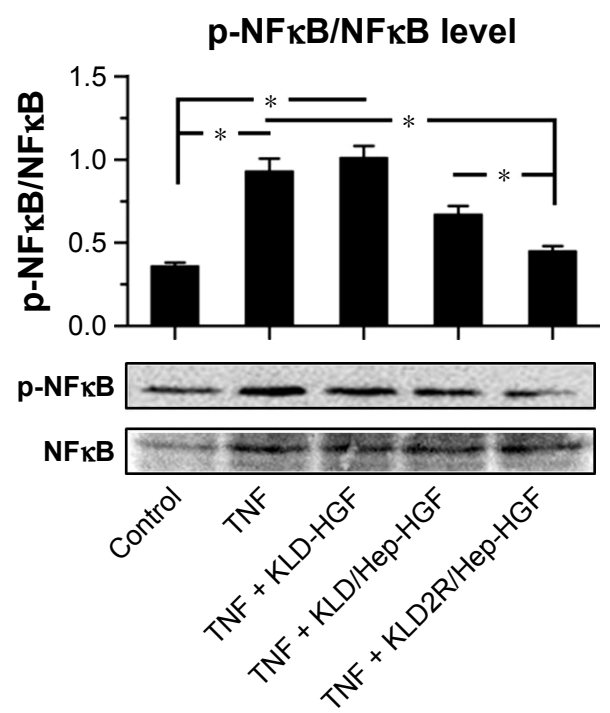

C

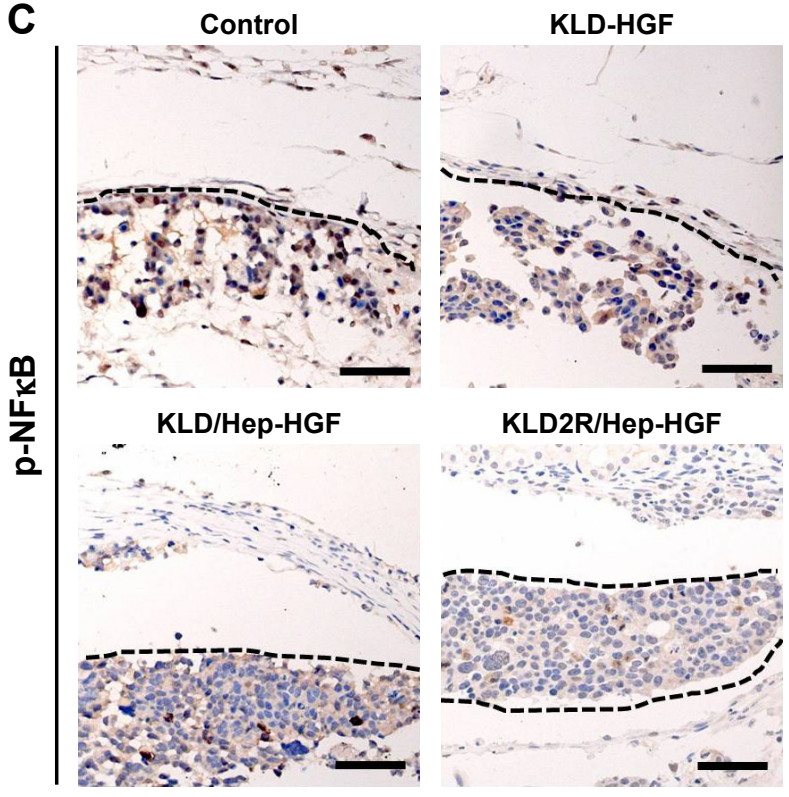

\section{Discussion}

Inflammation caused serious damage to islets and led to early graft loss after transplantation. ${ }^{2,3}$ SAP could serve as a flexible platform to deliver various chemical drugs and bioactive proteins. $^{12,15,16}$ In this study, we fabricated a cationic SAP/ Hep hybrid gel to deliver HGF and evaluated its protective effect on $\beta$-cell in transplantation.

KLD12 is an ionic-complementary peptide that contains positively charged lysines and negatively charged aspartic acids, and the net charge is zero. ${ }^{13}$ To obtain cationic SAPs, we added a series of arginines at the C-terminus of

\section{B}

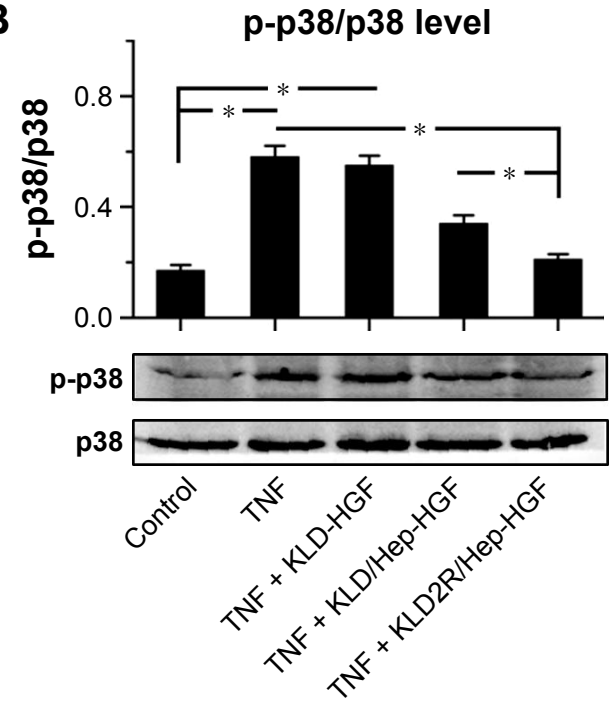

D

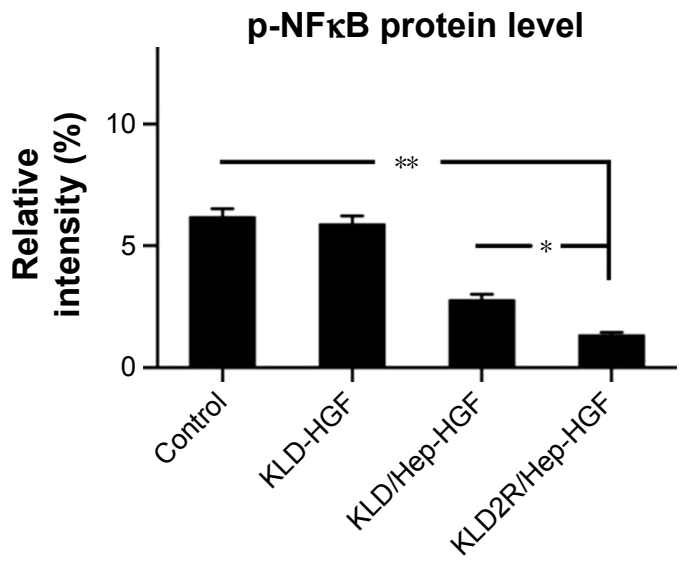

Figure 8 Effect of HGF-loaded SAP/Hep gel on inflammatory pathways.

Notes: Western blot and quantitative analysis of (A) p-NFKB p65 and (B) p-p38 MAPK protein levels in vitro. (C, D) IHC staining and quantitative analysis of p-NFKB p65 in vivo (scale bar $=50 \mu \mathrm{m}$ ). Data are mean $\pm S D$. $* P<0.05 ; * * P<0.01$. 200 $\times$ magnification.

Abbreviations: K, lysine; L, leucine; D, aspartate; R, arginine; HGF, hepatocyte growth factor; SAP, self-assembling peptide; Hep, heparin; MAPK, mitogen-activated protein kinase; IHC, immunohistochemistry; TNF, tumor necrosis factor. 
KLD (Table 1). Arginine is positively charged in almost all environments because of the presence of guanidinium group ( $\mathrm{pKa}=12.4$ ). To assay whether the addition of arginine disturbed the self-assembling process, the nanofiber and hydrogel formation of SAPs was analyzed. Similar to KLD, KLD1R and KLD2R formed cross-linked nanofiber structures and further changed to hydrogel under physiological saline conditions, but KLD3R did not form nanostructure and hydrogel, suggesting that incorporation of short amino acid motifs (less than 2 arginines) in the KLD did not affect its self-assembling process. KLD1R and KLD2R showed no obvious cytotoxicity and inflammation, and did not affect the insulin secretion of $\beta$-cells. It was well documented that SAPs rarely showed toxicity and immune response in various cell and animal experiments because they were prepared from natural amino acids. ${ }^{12,13}$ Our results also indicated that cationic SAP was a biocompatible nanomaterial to deliver bioactive cargos to $\beta$-cells.

Previous studies reported the linking of Hep to natural and polymer materials through covalent or noncovalent methods. ${ }^{18}$ Functionalized SAPs with Hep-binding motif showed strong binding affinity to Hep. ${ }^{20}$ Since Hep is highly negatively charged in physiological saline solution, it will stably bind to positively charged SAP through electrostatic interaction. Therefore, we developed a sample strategy to immobilize Hep by using cationic SAP. Our results showed the addition of low concentrations of Hep did not affect the gel formation by SAPs. Cationic KLD1R and KLD2R showed increased binding affinity and long-term retention for Hep compared to KLD. CD and FTIR results further revealed that KLD1R and KLD2R had $\beta$-sheet secondary structure, and the addition of Hep induced the shift of CD spectra and peak changes of FTIR spectra. Taken together, these results suggested that cationic SAP interacted with Hep and formed a nanocomposite. Our results indicated that cationic SAP might be used for the delivery of GFs due to its high binding affinity to Hep.

We then evaluated the effect of cationic SAP on HGF binding and release. Compared with KLD, cationic KLD1R and KLD2R showed high binding affinity to HGF, which may due to the electrostatic interactions between cationic arginines and negatively charged HGF. SAP/Hep composite further showed higher HGF binding affinity than SAP, suggesting that HGF bound to SAP nanofibers through affinity interaction with Hep. It had been reported that the release of small molecules and active proteins by SAP gel depends mainly on diffusion mechanism, and the release rate was influenced by molecular size and nanofiber density. ${ }^{16,17}$ In this study, KLD gel showed a rapid release of HGF within 2 days, while the KLD2R/Hep hybrid gel showed a sustained release of HGF for 7 days, and the addition of cells did not affect the slow release of HGF in the SAP/Hep gel. The slow release of HGF by KLD2R/Hep gel might be mediated by a two-step release mechanism, including binding affinity with Hep and molecular diffusion. These results suggested that KLD2R/ Hep is an efficient carrier for the sustained release of GFs.

$\beta$-cell destruction and apoptosis induced by inflammatory response was caused by multiple mechanisms, such as free radical formation, cell membrane injury, DNA strand breaks, and activation of proapoptotic pathways. ${ }^{3,21} \mathrm{HGF}$ showed anti-inflammatory effect in various organs, ${ }^{8}$ and $\beta$-cell function and islet transplantation outcomes were also improved. ${ }^{11}$ In this study, our results showed that inflammation reduced $\beta$-cell viability and induced $\beta$-cell apoptosis, but KLD-HGF gel did not reverse the $\beta$-cell injury, suggesting that rapid release of HGF could not protect $\beta$-cell from chronic inflammatory injury. In contrast, KLD2R/ Hep-HGF gel reduced $\beta$-cell death markedly and promoted $\beta$-cell survival under inflammatory conditions. Inflammatory cytokines such as IL-1 $\beta$ led to impaired insulin secretion and downregulation of $\mathrm{Pdx}-1$ in $\beta$-cell. ${ }^{22} \mathrm{Pdx}-1$ played an essential role in the insulin biosynthesis, and decreased Pdx-1 was associated with impaired insulin secretion function in $\beta$-cell. ${ }^{23}$ It had been reported that HGF gene therapy enhanced glucose sensing, mitogenesis, and insulin production in islet grafts. ${ }^{24}$ Our results further showed that slow release of HGF from KLD2R/Hep gel enhanced insulin secretion and $\mathrm{Pdx}-1$ expression in $\beta$-cell. These results indicated that KLD2R/Hep improved the survival and function of $\beta$-cell posttransplantation.

Increasing evidence indicated that inflammation played a critical role in early islet graft loss by inducing $\beta$-cell death and function impairment. After transplantation, islet was exposed to complement activation, local hypoxia, and endothelium injury, which in turn led to the release of inflammatory factors and infiltration of $\mathrm{T}$ cells and macrophages that interacted and destroyed $\beta$-cells. ${ }^{3}$ In this study, we observed abundant IL-1 $\beta$ expression and T-lymphocyte infiltration and activation of NFKB/p38 MAPK signaling in the transplanted $\beta$-cells. NFKB and MAPK signaling pathways played key role in the regulation of the expression of proinflammatory factors. ${ }^{25,26} \mathrm{HGF}$ has been shown to inhibit chemokines release in kidney by inhibiting NFKB pathway. ${ }^{27}$ Our results showed that the slow release of HGF from KLD2R/Hep gel inhibited IL-1 $\beta$ expression, T-lymphocyte infiltration, and $\mathrm{NF \kappa B} / \mathrm{p} 38$ pathways in the transplanted $\beta$-cells. These results 
indicated that KLD2R/Hep-HGF gel protected $\beta$-cells from inflammatory injury in a sustained manner.

\section{Conclusion}

In this study, we developed a cationic SAP/Hep hybrid gel to deliver HGF to protect $\beta$-cells from inflammatory injury. Cationic KLD1R and KLD2R showed increased binding affinity for Hep and HGF through electrostatic interaction. Cationic SAP/Hep gel showed a prolonged release of HGF because of the high binding affinity to Hep. In vitro and in vivo results showed that sustained release of HGF by KLD2R/Hep gel significantly enhanced $\beta$-cell survival and insulin secretion by inhibiting NFאB/p38 pathways, inflammatory cytokine expression, and lymphocyte infiltration in grafts. This study suggested that KLD2R/Hep hybrid gel is a promising carrier for local delivery of bioactive GFs for islet transplantation.

\section{Acknowledgments}

This work was supported by grants from National Natural Science Foundation of China (31200754, 81571808) and China Postdoctoral Science Foundation (2012M511931).

\section{Disclosure}

The authors report no conflicts of interest in this work.

\section{References}

1. Harlan DM, Kenyon NS, Korsgren O, Roep BO. Current advances and travails in islet transplantation. Diabetes. 2009;58:2175-2184.

2. Barshes NR, Wyllie S, Goss JA. Inflammation-mediated dysfunction and apoptosis in pancreatic islet transplantation: implications for intrahepatic grafts. J Leukoc Biol. 2005;77:587-597.

3. Kanak MA, Takita M, Kunnathodi F, Lawrence MC, Levy MF, Naziruddin B. Inflammatory response in islet transplantation. Int $J$ Endocrinol. 2014;2014:451035.

4. Bottino R, Fernandez LA, Ricordi C, et al. Transplantation of allogeneic islets of Langerhans in the rat liver: effects of macrophage depletion on graft survival and microenvironment activation. Diabetes. 1998;47: 316-323.

5. SoRelle JA, Itoh T, Peng H, et al. Withaferin A inhibits pro-inflammatory cytokine-induced damage to islets in culture and following transplantation. Diabetologia. 2013;56:814-824.

6. Bellin MD, Barton FB, Heitman A, et al. Potent induction immunotherapy promotes long-term insulin independence after islet transplantation in type 1 diabetes. Am J Transplant. 2012;12:1576-1583.

7. Nakamura T, Sakai K, Nakamura T, Matsumoto K. Hepatocyte growth factor twenty years on. Much more than a growth factor. J Gastroenterol Hepatol. 2011;26(S1):188-202.

8. Molnarfi N, Benkhoucha M, Funakoshi H, Nakamura T, Lalive PH. Hepatocyte growth factor: a regulator of inflammation and autoimmunity. Autoimmun Rev. 2015;14:293-303.
9. Gong R, Rifai A, Ge Y, Chen S, Dworkin LD. Hepatocyte growth factor suppresses proinflammatory NFkappaB activation through GSK3beta inactivation in renal tubular epithelial cells. J Biol Chem. 2008;283: 7401-7410.

10. Giannopoulou M, Dai C, Tan X, Wen X, Michalopoulos GK, Liu Y. Hepatocyte growth factor exerts its anti-inflammatory action by disrupting nuclear factor-kappaB signaling. Am J Pathol. 2008;173:30-41.

11. Garcia-Ocana A, Vasavada RC, Cebrian A, et al. Transgenic overexpression of hepatocyte growth factor in the beta-cell markedly improves islet function and islet transplant outcomes in mice. Diabetes. 2001;50:2752-2762.

12. Liu J, Zhao X. Design of self-assembling peptides and their biomedical applications. Nanomedicine (Lond). 2011;6:1621-1643.

13. Zhao X, Zhang S. Molecular designer self-assembling peptides. Chem Soc Rev. 2006;35:1105-1110.

14. Liu J, Song H, Zhang L, Xu H, Zhao X. Self-assembly-peptide hydrogels as tissue-engineering scaffolds for three-dimensional culture of chondrocytes in vitro. Macromol Biosci. 2010;10:1164-1170.

15. Liu J, Zhang L, Yang Z, Zhao X. Controlled release of paclitaxel from a self-assembling peptide hydrogel formed in situ and antitumor study in vitro. Int J Nanomed. 2011;6:2143-2153.

16. Gelain F, Unsworth LD, Zhang S. Slow and sustained release of active cytokines from self-assembling peptide scaffolds. J Control Release. 2010;145:231-239.

17. Nagai Y, Unsworth LD, Koutsopoulos S, Zhang S. Slow release of molecules in self-assembling peptide nanofiber scaffold. $J$ Control Release. 2006;115:18-25.

18. Liang Y, Kiick KL. Heparin-functionalized polymeric biomaterials in tissue engineering and drug delivery applications. Acta Biomater. 2014; $10: 1588-1600$.

19. Ahola MS, Sailynoja ES, Raitavuo MH, Vaahtio MM, Salonen JI, Yli-Urpo AU. In vitro release of heparin from silica xerogels. Biomaterials. 2001;22:2163-2170.

20. Rajangam K, Behanna HA, Hui MJ, et al. Heparin binding nanostructures to promote growth of blood vessels. Nano Lett. 2006;6:2086-2090.

21. Rabinovitch A, Suarez-Pinzon WL. Cytokines and their roles in pancreatic islet beta-cell destruction and insulin-dependent diabetes mellitus. Biochem Pharmacol. 1998;55:1139-1149.

22. Andersson AK, Borjesson A, Sandgren J, Sandler S. Cytokines affect PDX-1 expression, insulin and proinsulin secretion from iNOS deficient murine islets. Mol Cell Endocrinol. 2005;240:50-57.

23. Brissova M, Shiota M, Nicholson WE, et al. Reduction in pancreatic transcription factor PDX-1 impairs glucose-stimulated insulin secretion. J Biol Chem. 2002;277:11225-11232.

24. Mahato RI. Gene expression and silencing for improved islet transplantation. J Control Release. 2009;140:262-267.

25. Abdelli S, Ansite J, Roduit R, et al. Intracellular stress signaling pathways activated during human islet preparation and following acute cytokine exposure. Diabetes. 2004;53:2815-2823.

26. Omori K, Valiente L, Orr C, et al. Improvement of human islet cryopreservation by a 38 MAPK inhibitor. Am J Transplant. 2007;7: 1224-1232.

27. Gong R, Rifai A, Tolbert EM, Biswas P, Centracchio JN, Dworkin LD. Hepatocyte growth factor ameliorates renal interstitial inflammation in rat remnant kidney by modulating tubular expression of macrophage chemoattractant protein-1 and RANTES. J Am Soc Nephrol. 2004;15: 2868-2881. 


\section{Supplementary material}

A

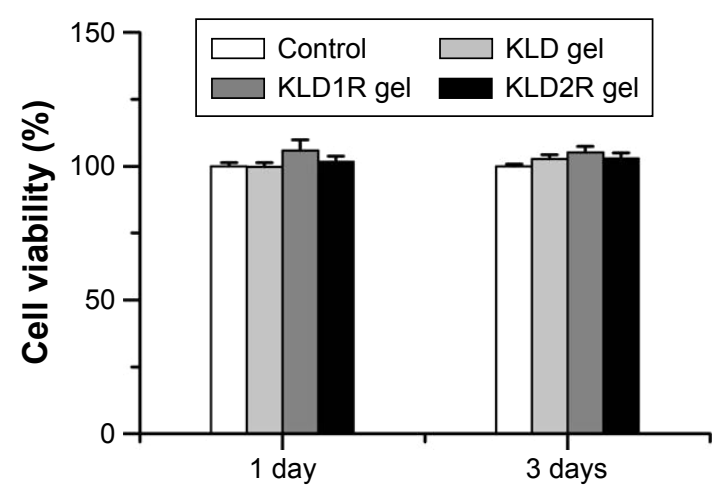

C

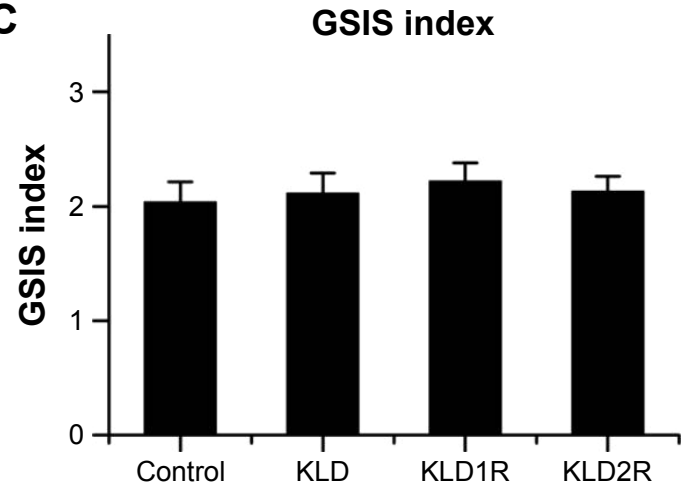

B

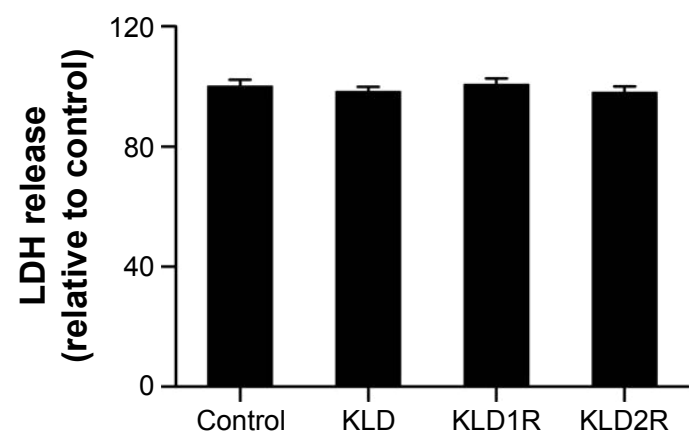

D

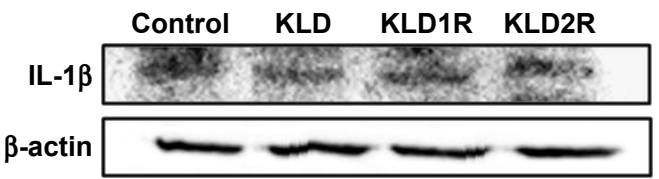

Figure SI Effect of SAPs on cell viability, function, and inflammation of INS-I $\beta$-cells.

Notes: (A) Cell viability assayed by CCK-8 test. (B) Evaluation of cytotoxicity by LDH release assay at 24 hours. (C) Evaluation of $\beta$-cell functions by GSIS test at 24 hours. (D) Evaluation of $\beta$-cell inflammatory factor expression by WB at 24 hours. Data are mean \pm SD.

Abbreviations: K, lysine; L, leucine; D, aspartate; R, arginine; SAP, self-assembling peptide; CCK, cell counting kit; LDH, lactate dehydrogenase; GSIS, Glucose-stimulated insulin secretion test; WB, Western Blot; IL, interleukin.

\section{Publish your work in this journal}

The International Journal of Nanomedicine is an international, peerreviewed journal focusing on the application of nanotechnology in diagnostics, therapeutics, and drug delivery systems throughout the biomedical field. This journal is indexed on PubMed Central, MedLine, CAS, SciSearch $®$, Current Contents ${ }^{\circledR} /$ Clinical Medicine,
Journal Citation Reports/Science Edition, EMBase, Scopus and the Elsevier Bibliographic databases. The manuscript management system is completely online and includes a very quick and fair peer-review system, which is all easy to use. Visit http://www.dovepress.com/ testimonials.php to read real quotes from published authors. 